\title{
Mouse Chromosome 11
}

\author{
Arthur M. Buchberg, ${ }^{1, *}$ Marion S. Buckwalter, ${ }^{2}$ and Sally A. Camper ${ }^{2}$ \\ ${ }^{1}$ Jefferson Cancer Institute, Thomas Jefferson University, 233 South 10th Street, Philadelphia, Pennsylvania 19107-5541, USA; \\ ${ }^{2}$ Department of Human Genetics, University of Michigan Medical School, Ann Arbor, Michigan 48109-0618, USA
}

Received February 27, 1992

\section{Introduction}

A consensus linkage map of Chr 11 was constructed based on several multilocus genetic crosses, and the remainder of the loci were placed on this foundation (Buchberg et al. 1991). This report expands on the previous consensus map (Buchberg et al. 1991) and includes over 20 new loci that have been recently mapped on Chr 11. The cytogenetic characterization of mouse Chr 11 and the linkages of the human homologs of the genes mapping to mouse $\mathrm{Chr} 11$ are summarized in this report. The resulting consensus linkage map is intended to be used as a guide for genetic, physical, and molecular analyses of Chr 11 .

\section{Locus list}

In total, 167 loci are currently known to be assigned to mouse Chr 11 (Table 1). The new loci include the wobbler mutation $(w r)$, insulin-dependent diabetes susceptibility-4 (Idd-4), and an imprinted gene $(\mathrm{Om})$ associated with embryonic lethality. Additionally, several new molecular markers have been localized to Chr 11 including angiotensin-converting enzyme (Ace), a transplantation antigen (AntP91a), acid $\alpha$ glucosidase (Gaa), interferon regulatory factor-1 (Irf-1), UDP- $N$ acetylglucosamine: $\alpha$-3-D-mannoside $\beta-1,2-N$-acetylglucosaminyltransferase I (Mgat-1), retinoic acid receptor $\alpha$ (Rara), sodium channel $\alpha$ subunit, skeletal

${ }^{*}$ Chair of Committee for Mouse Chromosome 11 muscle $(S c n 4 a)$, transcription factor $2(T c f-2)$, vacuolar (endomembrane) proton pump subunit-1 (Vpp-1). The largest class of new markers consisted of microsatellites, mononucleotide repeats, and anonymous DNA sequences (Table 1 and Table 7). Many of the new DNA markers were positioned by use of recombinant inbred (RI) lines.

The mouse gene symbols and official gene names are given with antiquated and alternate gene names. The human gene symbol and linkage are given where known. A reference is included for the mouse and human linkages. In the interest of space, an original reference either describing the gene or its localization to mouse Chr 11 was selected for inclusion in Table 1. Because many of the loci on Chr 11 have been mapped by several methods, interested readers are encouraged to refer to GBASE, OMIM, and the chapter on mouse-human comparative maps, which appears at the end of this issue, for additional references. Gene descriptions are provided for most of the phenotypic and biochemical markers in Green (1989).

\section{Consensus map}

Figure 1 shows the current consensus linkage map of mouse Chr 11. The map was originally constructed by first creating a skeleton map based on the multi-locus backcross analyses (Table 2 and Table 3; Buchberg et al. 1991). No significant differences in recombination distances were observed among the several backcrosses that have loci in common. These include Backcross A (Mus spretus $\times$ C57BL/6J) $\times$ C57BL/6J, Backcross B (CASA $/ \mathrm{Rk} \times \mathrm{DF} / \mathrm{B}-d f / d f) \times \mathrm{DF} / \mathrm{B}-d f / d f$, Backcross $\mathrm{C}(\mathrm{C} 3 \mathrm{H} / \mathrm{HeJ}-$ gld $\times M$. spretus $) \times \mathrm{C} 3 \mathrm{H} / \mathrm{HeJ}$ 
Table 1. Locus list for mouse Chr 11.

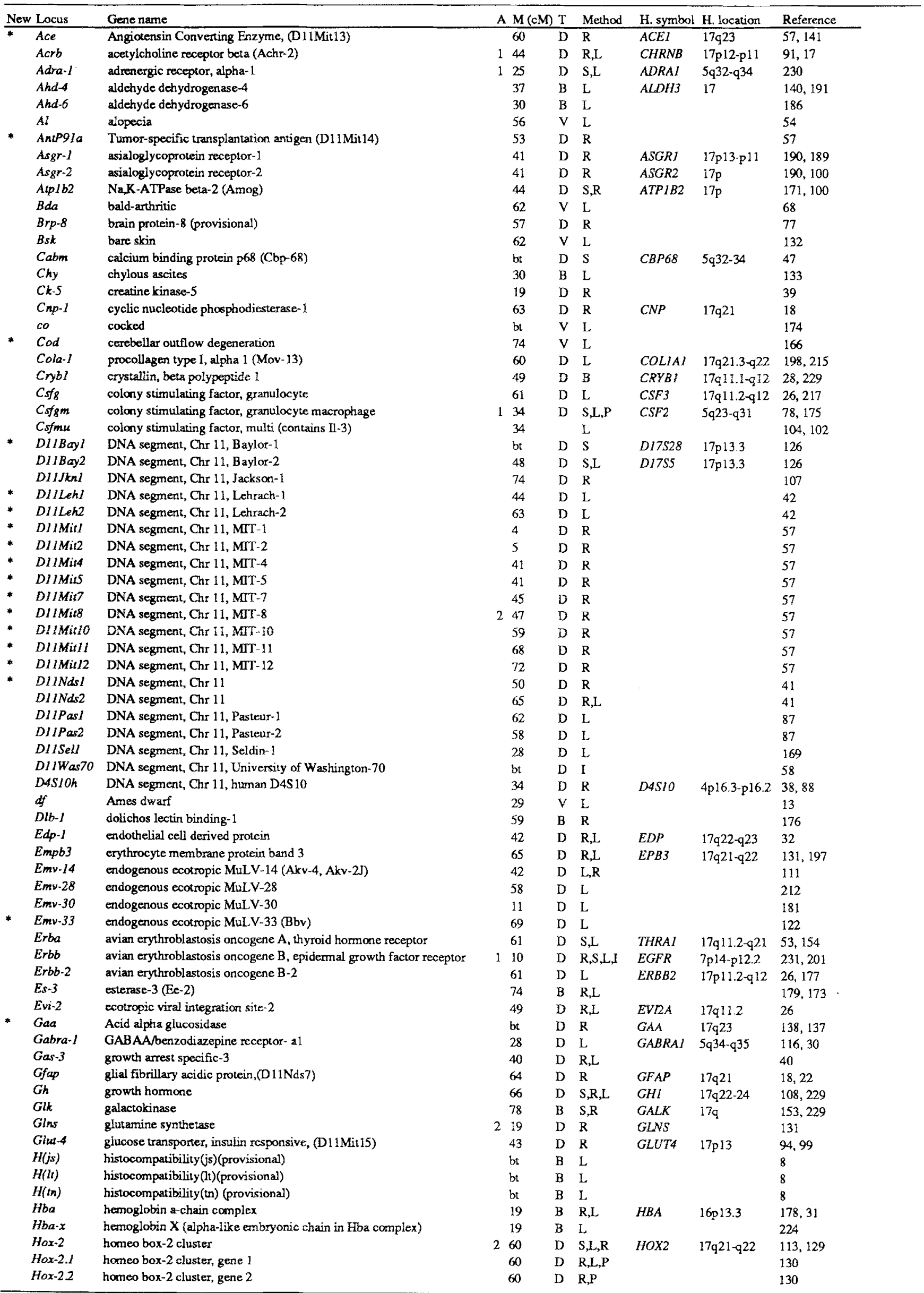


Table 1. Continued.

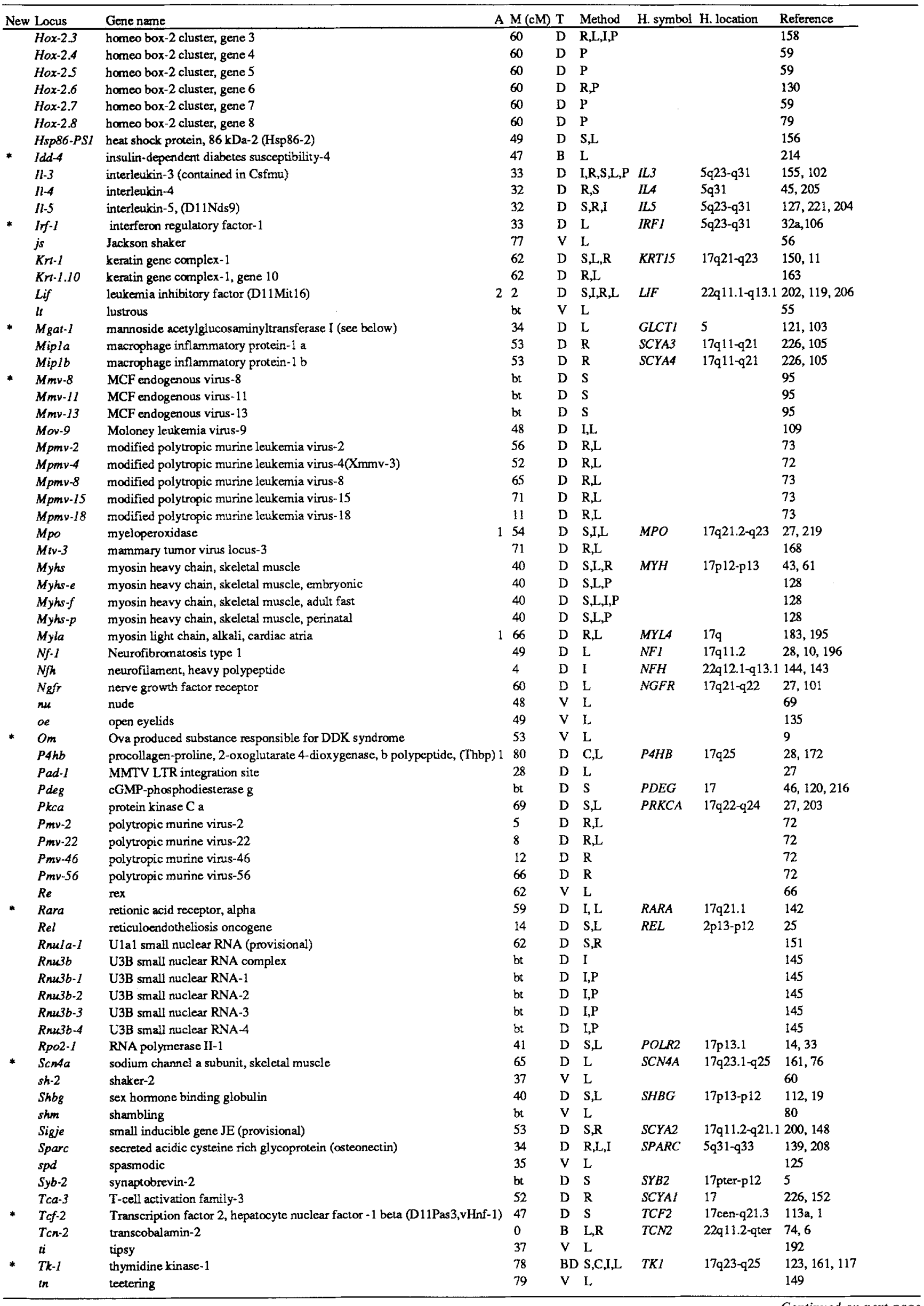


Table 1. Continued.

\begin{tabular}{|c|c|c|c|c|c|c|c|}
\hline New Locus & Gene name & A $M(\mathrm{cM})$ & & Method & H. symbol & H. location & Reference \\
\hline$T r$ & trembler & 37 & $\bar{V}$ & $\bar{L}$ & & & 67 \\
\hline Trp53 & transformation-related protein 53 & 44 & D & $\mathrm{S}, \mathrm{L}, \mathrm{I}$, & TP53 & $17 \mathrm{p} 13.1$ & $232,44,147$ \\
\hline Ts & tail-short & 69 & $\mathrm{~V}$ & $\mathrm{~L}$ & & & 157 \\
\hline Tse-1 & tissue specific extinction -1 , of TAT & bt & B & $\mathrm{s}$ & TSE1 & $17 \mathrm{q} 23-\mathrm{q} 24$ & 117, \\
\hline Umph-2 & uridine monophosphat ase-2 & bt & B & $\mathrm{s}$ & UMPH 2 & $17 \mathrm{q} 23.2-\mathrm{q} 25.3$ & 207,225 \\
\hline$v b$ & vibrator & 37 & $\mathrm{~V}$ & $\mathrm{~L}$ & & & 222,124 \\
\hline * Vpp-1 & vacuolar (endomembrane) proton pump subunit-1 $(116 \mathrm{kDa})$ & bt & D & $\mathbf{s}$ & VPPI & $17 \mathrm{q} 21$-qter & 170 \\
\hline$v t$ & vestigial-tail & 29 & $\mathrm{~V}$ & $\mathrm{~L}$ & & & 92 \\
\hline$w a-2$ & waved-2 & 7 & $\mathrm{~V}$ & $\mathrm{~L}$ & & & 115 \\
\hline Wnt -3 & wingless-rel ated MMTV integration site- 3 (Int-4) & 64 & $\mathrm{D}$ & $\mathrm{L}$ & WNT3 & $17 \mathrm{q} 21-\mathrm{q} 22$ & 27,182 \\
\hline Wnt-3A & wingless-related MMTV integration site- $3 \mathrm{~A}(\mathrm{Int}-4 \mathrm{~A})$ & bt & $\mathrm{D}$ & & & & 167 \\
\hline *wr & wobbler & 12 & $\mathrm{~V}$ & $\mathrm{~L}$ & & & 114 \\
\hline$X m v-4$ & xenotropic murine leukemia vinus- 4 & bt & $\mathrm{D}$ & $\mathrm{s}$ & & & 95 \\
\hline$X m v-5$ & xenotropic murine leukemia virus-5 & bt & $\mathrm{D}$ & $S$ & & & 95 \\
\hline$X m v-20$ & xenotropic murine leukernia virus- 20 & 57 & $\mathrm{D}$ & $\mathrm{R}, \mathrm{L}$ & & & 71 \\
\hline$X m v-42$ & xenotropic murine leukemia vinus- 42 & 56 & $\mathrm{D}$ & $R, L$ & & & 71 \\
\hline$X m v-63$ & xenotropic murine leukemia vinus- 63 & 1 & D & $\mathrm{L}$ & & & 70 \\
\hline$Z f_{p}-2$ & zinc finger protein-2 & 48 & D & $\mathrm{S}, \mathrm{L}$ & & & 164 \\
\hline$Z f p-3$ & zinc finger protein-3 (Fnp-1) & 44 & D & $R, L$ & ZFP3 & 17 pter-p 12 & 7 \\
\hline
\end{tabular}

An asterisk in the column "New" represents new mapping information for those genes (29). Approved gene designation (in column labeled "Locus") is presented along with alternate or archaic locus designations (in column labeled "Gene name"). Recommended reference loci are indicated in the column labeled "A," with " 1 " indicating primary anchor and " 2 " indicating secondary anchor. The approximate map position of each locus relative to the centromere is given in $\mathrm{cM}$ in the column labeled " $\mathrm{M}$." genes whose position is not known are listed at the bottom of Fig. 1 and are indicated here by "bt." The column labeled " $T$ " indicates whether the locus is represented by a DNA

\section{-gld, and Backcross F (NFS/N $\times$ M.m. musculus $) \times$} M.m. musculus.

Loci that were mapped in a single two-point linkage analysis where gene order is not known were not placed on the map. The information for these loci is listed in the bottom right of Fig. 1, including the gene name and distance from the known gene. Loci that were placed on Chr 11 only by analysis of recombinant inbred (RI) strains were included on the map, but in some cases gene order and distances are ambiguous. We encourage evaluation of the primary RI strain data included in Table 4.

The results of this compilation of data is shown in Fig. 1 as a linear map. An important note is that this map should be used as a guide for gene localization. Gene order is known with certainty only for those loci mapped in the same cross (Table 2).

Genes that have been localized by in situ hybridization (Table 5) are noted to the left of the chromosome with the regional localization in parentheses. The genes localized to mouse Chr 11 solely by in situ hybridization (Table 5) are listed at the bottom of Fig. 1. Genes whose human homologs have also been localized are underlined, and their human chromosomal locations are shown to the right of the chromosome. Genes that have been assigned to Chr 11 by somatic sequence or clone (D), a biochemical, protein, or immunological assay (B), or by a visible or other phenotype (V). The method by which the locus was mapped (shown in the column labeled "Method") are in situ hybridization (I), somatic cell genetics (S), radiation hybrid analysis $(\mathrm{H})$, RI analysis $(\mathrm{R})$, linkage analysis (L), cytogenetic analysis (C), deletion analysis (D), and physical mapping (P). Also presented are the human gene symbols and human gene location. Original references describing the human and mouse gene characterization and map locations are listed. More complete descriptions of some genes can be found in Green (81).

cell hybrid analysis or in situ hybridization are listed at the bottom of Fig. 1. Anchor loci are boxed.

\section{Multilocus crosses}

Table 2 and Table 3 contain the data derived from multilocus (three or more genes) crosses involving markers on mouse Chr 11. None of the multi-locus crosses present conflicting gene orders for loci mapped in common. A total of 88 loci have been mapped in the multi-locus crosses (Table 2), spanning $80 \mathrm{cM}$ (the predicted length of Chr 11). Each column in this table (Table 2) represents a single cross involving three or more markers. The dots within the column denote the loci that were mapped in the cross. The shaded areas identify loci that were inseparable in the given cross. Some loci that were not separable in backcrosses were separated by recombination in the analysis of independent crosses or RI lines, permitting determination of gene order. Table 3 lists the experimentally determined map distance ( \pm standard error) that was obtained in each of the multi-locus crosses. The utility of presenting the information in Table 2 is that it simplifies determining which genes have been mapped with respect to each other, hence allowing for identification of which loci are ordered unambiguously.
Fig. 1. Consensus linkage and cytogenetic map of mouse Chr 11. The chromosome on the right represents the consensus linkage map of mouse Chr 11. The genes mapping to mouse Chr 11 are presented on the right of the chromosome, and the distance from the centromere is indicated on the left of the chromosome. Genes that are listed along the left of the chromosome have also been localized on the cytogenetic map (on the left of the figure), with the cytogenetic location shown to the left of the chromosome (Table 5). Loci that are underlined have also been localized to human chromosomes; their locations on human chromosomes are shown to the right of the chromosome (Table 1). Below the chromosome are those loci mapping to Chr 11 by somatic cell hybrid analysis or in situ hybridization methods; their cytogenetic and human locations are shown. Genes in the lower right corner have been mapped to $\mathrm{Chr} 11$, but location could not be determined. Loci that are boxed represent anchor loci (Table 1, text). 


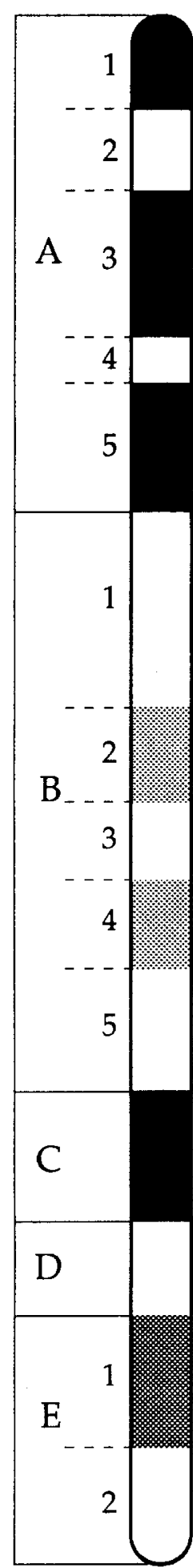

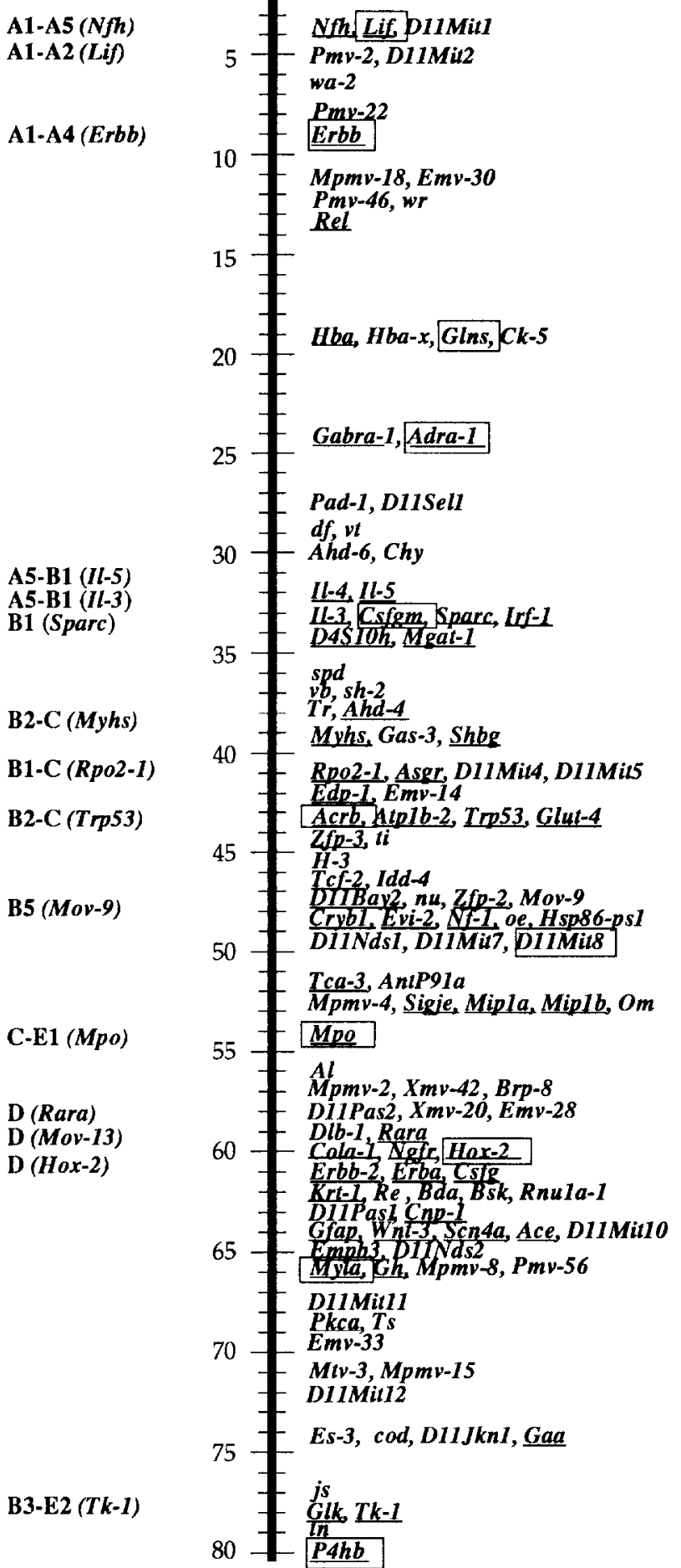

A1-A5 (Nfh)
A1-A2 (Lif)

A5-B1 (Il-3)

B1 (Sparc)

B2-C (Myhs)

B1-C (Rpo2-1)

B2-C (Trp53)

B5 (Mov-9)

C-E1 (Mpo)

D (Rara)

D (Mov-13)

$\mathrm{D}($ Hox-2)

$80 \multimap P 4 h b$ 22q11.2-qter

22q12.1-q13.1, 22q11-q12

7p14-p12

2p13-p12

16p13.3

$5 q 34-q 35,5 q 32-q 34$

$5 q 31,5 q 23-q 31$

5q23-q31, 5q23-q31, 5q31-q33, 5q23-q31

4p16.3-p16.2, 5

17

17p13, 17p13-p12

17p13.1, 17p13-p11

17q22-q23

17p12-p11, 17p, 17p13.1, 17p13

17pter-p12

17cen-q21.3

17q11.1-q12, 17q11.2, 17q11.2

17

17q11.2-q21.1, 17q11-q21, 17q11-q21

17q21.3-q23

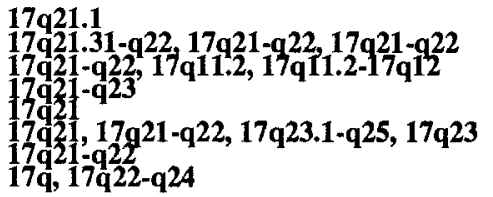

$17 q 22-q 24$

$17 q 23$

$17 q 21-q 22,17 q 23.2-q 25.3$

$17 q 25$

$\begin{array}{ll}\text { Cabm } & 5 \mathrm{q} 32-\mathrm{q} 34 \\ \text { co } & 17 \mathrm{q} 13.3 \\ \text { D11Bay1 } & \\ \text { D11Was70 (cen) } \\ \text { Mmv-8 } & \\ \text { Mmv-11 } & \\ \text { Mmv-13 } & \\ \text { Pdeg } & 17 \mathrm{q} 21 \\ \text { Rnu } 3 b(C-D) & \\ \text { Syb-2 } & 17 \mathrm{pter}-\mathrm{p} 12 \\ \text { Tse-1 } & 17 \mathrm{q} 23-\mathrm{q} 24 \\ \text { Umph-2 } & 17 \mathrm{q} 23.2-\mathrm{q} 25.2 \\ \text { Vpp-1 } & 17 \mathrm{q} 21-\mathrm{qter} \\ \text { Wnt-3A } & \\ \text { Xmv-4 } & \\ \text { Xmv-5 } & \end{array}$

shm $-1.5 \pm .7-R e$ lt $-3.9 \pm 1.7-R e$ $H(j s)-27 \pm 8-j s$ $H(l t)-32 \pm 7-l t$ $H(t n)-30 \pm 8-t n$ 
Table 2. Order list.

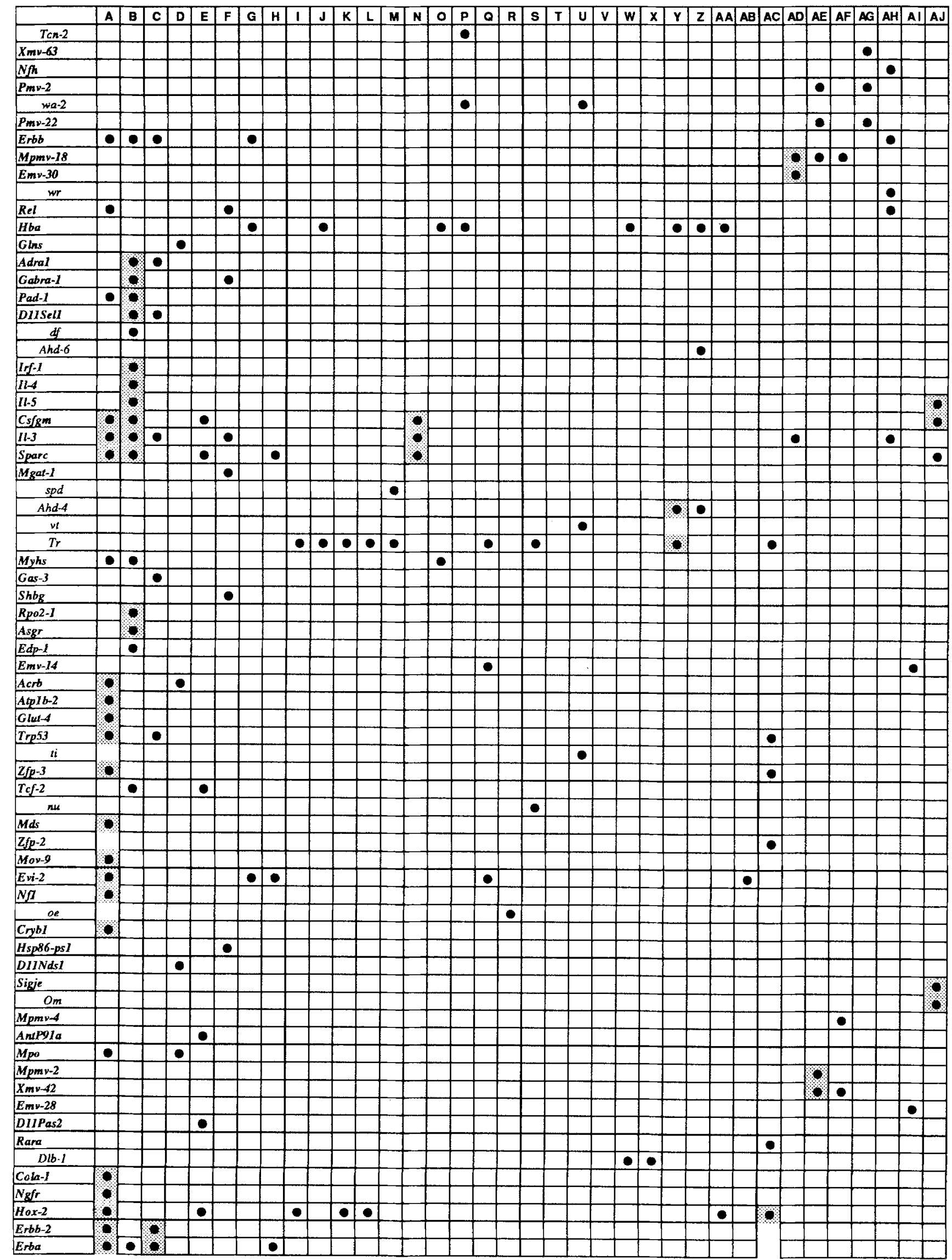


Table 2. Continued.

\begin{tabular}{|c|c|c|c|c|c|c|c|c|c|c|c|c|c|c|c|c|c|c|c|c|c|c|c|c|c|c|c|c|c|c|c|c|c|c|c|c|}
\hline & A & B & c & D & $E$ & $F$ & G & $H$ & 1 & $J$ & $\mathbf{K}$ & $\mathrm{L}$ & $M$ & \begin{tabular}{|l|}
$\mathbf{N}$ \\
\end{tabular} & 0 & $P$ & 0 & $\mathbf{R}$ & 5 & $T$ & $u$ & $\mathrm{v}$ & $w$ & $x$ & $Y$ & $z$ & AA & $\mathbf{A B}$ & $A C$ & AD & AE & \begin{tabular}{|l|l} 
AF \\
\end{tabular} & \begin{tabular}{l|l}
$\mathbf{A G}$ & $\mathbf{A}$
\end{tabular} & $\mathbf{A H}$ & Al $\mathrm{A}$ & as \\
\hline$C_{\text {eff }}$ & 1 & & & & & & & & & & & & & & & & & & & & & & & & & & & & $=$ & & & & & & & \\
\hline$K_{n-1}$ & & & & & & & & & $\%$ & $\%$ & $\%$ & & & & & & & & & & & & & & & & & & 18 & & & & & & & \\
\hline$R_{e}$ & & & & & & & & & 2 & 8 & 80 & $\bullet$ & 0 & & & & 0 & 0 & $\bullet$ & 0 & $\bullet$ & 0 & & - & 0 & & & 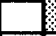 & 8 & & & & & & & \\
\hline Dl1Pal & & & & & 0 & & & & & & & & & & & & & & & & & & & & & & & & & & & & & & & \\
\hline Gfap & $x$ & & & - & $\bullet$ & & & & & & & & & & & & & & & & & & & & & & & & & & & & & & & \\
\hline$W_{n t-3}$ & 楚 & & & & & 0 & & & & & & & & & & & & & & & & & & & & & & 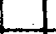 & & & & 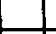 & & & & \\
\hline Sconde & & & & & & & & & & & $\bullet$ & & & & & & & & & & & & & & & & & & & & 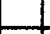 & & & & & \\
\hline$M \operatorname{men-8}$ & & & & & & & & & & & & & & & & & & & & & & & & & & & & & & & - & 1 & & & & \\
\hline Myle & $x$ & & & $\bullet$ & $\bullet$ & & & & & & & & & & e & & & & & & & & & & & & & & & & & & & & & \\
\hline$G h$ & & 0 & & & & & 은 & e & & & & & & & & & & & & & & & & & & & & $e$ & & & & & & & & \\
\hline$T s$ & & & & & & & & & & & & & & & & & & & & & & 0 & & & & & & & & & & & & & & \\
\hline Pkea & 인 & & 0 & & & & & & & & & & & & & & & & & & & & & & & & & & & & & & & & & \\
\hline Mpmp-15 & & & & & & & & & & & & & & & & & & & & & & & & & & & & & & & & 18 & 1 & & & \\
\hline Mtr-3 & & & & & & & & & & & & & & & & & & & & & & & & & & & & 0 & & & & 8 & 8 & & & \\
\hline$E_{s-3}$ & & & & & 0 & & & 0 & & 으 & & & & & 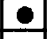 & & 아 & 6 & & 10 & & - & 0 & 으 & & & 드 & & & & & - & - & & 으 & 의 \\
\hline is & & & & & & & & & & & & & & & & & & & & 10 & & & & & & & & & & & & 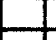 & & & & \\
\hline$T k-1$ & & & & & & & & & & & $e$ & & & & & & - & - & 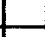 & - & & & & & & & 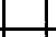 & - & - & & & - & & & & \\
\hline$P\{h b$ & 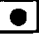 & & & & & & & & & & & & & & & & & & & & & & & & & & & & & & & & & & & \\
\hline
\end{tabular}

The data presented in Tables 2 and 3 represent the basis of the linkage map (Fig. 1). Order for closely linked genes that have not yet been mapped with respect to each other was inferred on the basis of recombination distances. The presentation of a consensus linkage map is valuable and provides a basis for critical analysis of ambiguous areas. Unless genes are mapped relative to each other, inaccuracies may remain in the consensus map. These ambiguities can be minimized if more common anchor loci are utilized in the different crosses.

\section{RI strain data}

Table 4 is a compilation of the strain distribution patterns of genes mapped in RI strains. In the analysis of RI lines, the high frequency of double recombinants makes ordering of genes over long distances difficult. However, RI analysis can be extremely useful for determining gene order over short distances. Backcross analysis of Chr 11 markers revealed several clusters of genes in which gene order could not be determined, for example, Sparc, $I l-3, I l-4, I l-5$, and $C s f g m$. RI analysis showed recombination occurring between Sparc and $I l-5$ and also between $I l-3$ and (Il-4, Il-5), suggesting the gene order displayed on the consensus map.

\section{Cytogenetics}

Genes that have been cytogenetically localized to $\mathrm{Chr}$ 11 are listed in Table 5. The physical locations reported for these genes (Table 5) are consistent with their relative order in the consensus linkage map (Fig. 1).

The known chromosomal variants involving Chr 11 are listed in Table 6 along with the breakpoint regions. The chromosomal variants include inversions, trans- locations, and Robertsonian fusions. As the breakpoints become better defined relative to molecular markers, it may be possible to utilize some of these chromosomal variants to gain access to different regions of the chromosome.

\section{Comparative maps}

Mouse Chr 11 contains at least seven homology segments, including genes whose human homologs map to human Chrs 2, 4, 5, 7, 16, 17, and 22 (Nadeau et al. 1991). Table 1 lists the locus designations and chromosomal locations of the human homologs of the corresponding mouse loci. This information is also shown in Fig. 1, facilitating the identification of regions of synteny conservation. The two most extensive regions of conserved synteny include the medial region of mouse Chr 11, which exhibits synteny conservation with human Chr 5q23-q34, and the distal half of mouse Chr 11, which displays synteny conservation with human $\mathrm{Chr}$ 17. To date, all of the genes that have been unambiguously localized to either the p or q arms of human Chr 17, when mapped in the mouse, have been assigned to mouse Chr 11 (Munke and Francke 1987; Buchberg et al. 1989, 1990; Nadeau et al. 1989, 1991; and Buckwalter et al. 1991). In contrast, genes from human $\mathrm{Chr}$ 5q22-q35 have also been localized to mouse Chr 18 (Nadeau et al. 1991). The localization of several new genes and genes that had previously been simply assigned to Chr 11 has augmented these evolutionary relationships and strengthened the suggestion of a region of synteny conservation including the most proximal region of mouse $\mathrm{Chr} 11$ and human $\mathrm{Chr}$ 22q11-qter. Synteny conservation between mouse and humans was used successfully in the previous chromosome report to predict the localization of genes such as Lif, Nfh, Glut-4, Syb-2, and Tk-1, which were assigned to mouse Chr 11 by somatic cell hybrid analysis or in situ hybridization (Buchberg et al. 1991). 
Table 3. This table presents the gene order (proximal to distal) and recombination distance ( $\mathrm{cM} \pm$ standard error) for the multilocus crosses presented in Table 2 .

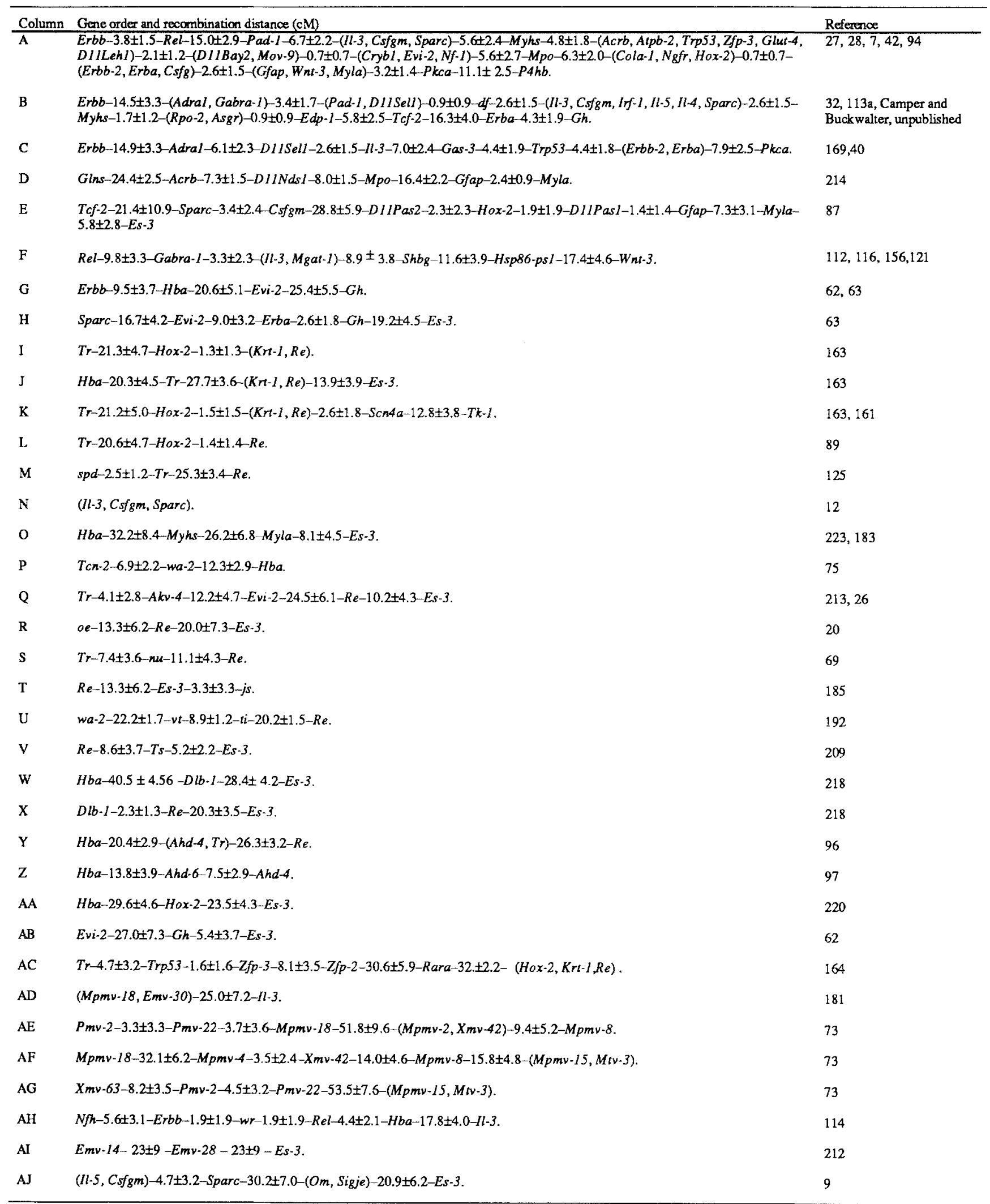


Table 4. SDPs of Chr 11 loci typed in BXD RI strains. B and D represent alleles derived from C57BL/6J and DBA/2J, respectively.

\begin{tabular}{|c|c|c|c|c|c|c|c|c|c|c|c|c|c|c|c|c|c|c|c|c|c|c|c|c|c|c|c|c|}
\hline $\begin{array}{l}\text { Locus } \\
\text { Pmv-22 }\end{array}$ & $\frac{1}{B}$ & $\frac{2}{\mathrm{~B}}$ & $\frac{4}{-}$ & $\begin{array}{l}5 \\
\end{array}$ & $\begin{array}{l}6 \\
\mathrm{D}\end{array}$ & $\begin{array}{l}8 \\
B\end{array}$ & $\frac{9}{D}$ & $\overline{\bar{B}}$ & $\frac{12}{\mathrm{~B}}$ & $\begin{array}{l}13 \\
\mathrm{D}\end{array}$ & $\frac{14}{D}$ & $\frac{15}{\mathrm{~B}}$ & $\frac{16}{\mathrm{~B}}$ & $\frac{18}{\mathrm{D}}$ & $\frac{19}{B}$ & $\frac{20}{\mathrm{D}}$ & $\frac{21}{B}$ & $\frac{22}{B}$ & $\begin{array}{l}23 \\
\mathrm{~B} \\
\mathrm{X}\end{array}$ & $\begin{array}{l}24 \\
\mathrm{D}\end{array}$ & $\frac{25}{B}$ & $\frac{27}{\mathrm{D}}$ & $\frac{28}{D}$ & $\begin{array}{l}29 \\
\mathrm{D}\end{array}$ & $\frac{30}{\mathrm{~B}}$ & $\frac{31}{D}$ & $\frac{32}{\mathrm{D}}$ & $\begin{array}{l}\text { Reference } \\
72\end{array}$ \\
\hline DIIMit2 & - & B & - & B & $\mathrm{D}$ & B & D & B & B & $\mathrm{D}$ & $\mathrm{D}$ & $\begin{array}{l}\mathrm{B} \\
\mathrm{x}\end{array}$ & - & $\mathrm{D}$ & B & $\mathrm{D}$ & B & B & D & D & B & $\mathrm{D}$ & D & D & - & - & - & 57 \\
\hline Glns & B & D & - & B & D & B & $\begin{array}{l}D \\
x\end{array}$ & B & B & D & $\mathrm{D}$ & $\mathrm{D}$ & B & $\mathrm{D}$ & $B$ & D & B & B & $\mathrm{D}$ & D & B & $\mathrm{D}$ & D & D & $\mathrm{D}$ & $\mathrm{D}$ & $\mathrm{D}$ & 131 \\
\hline$H b a$ & B & D & - & B & D & B & B & B & B & D & $\mathrm{D}$ & D & B & D & $\stackrel{\AA}{\mathrm{D}}$ & D & B & B & $\begin{array}{l}X \\
B\end{array}$ & D & B & D & D & D & $\mathrm{D}$ & - & - & 199 \\
\hline Sparc & $\hat{D}$ & $\mathrm{D}$ & - & B & D & B & B & B & $\stackrel{\mathrm{X}}{\mathrm{D}}$ & $\mathrm{D}$ & $\stackrel{x}{B}$ & $\begin{array}{l}\mathbf{X} \\
\mathbf{B}\end{array}$ & $\stackrel{\mathbf{x}}{\mathbf{D}}$ & $\mathrm{D}$ & $\begin{array}{l}\mathbf{X} \\
\mathbf{B}\end{array}$ & $\begin{array}{l}\mathrm{x} \\
\mathrm{B}\end{array}$ & $\stackrel{\mathrm{x}}{\mathrm{D}}$ & B & B & $\begin{array}{l}\mathbf{X} \\
\mathbf{B}\end{array}$ & B & $\begin{array}{l}\mathrm{x} \\
\mathrm{B}\end{array}$ & D & D & $\begin{array}{l}\mathbf{x} \\
\mathbf{B}\end{array}$ & D & D & 139 \\
\hline $\begin{array}{l}\text { ll-5 } \\
\text { D4SIOh }\end{array}$ & $\begin{array}{l}\mathrm{D} \\
\mathrm{D}\end{array}$ & $\begin{array}{l}\mathrm{D} \\
\mathrm{D}\end{array}$ & - & $\begin{array}{l}\text { B } \\
\text { B }\end{array}$ & $\begin{array}{l}\mathrm{D} \\
\mathrm{D}\end{array}$ & $\underset{\mathrm{B}}{\mathrm{B}}$ & $\begin{array}{l}\mathrm{B} \\
\mathrm{B}\end{array}$ & $\begin{array}{l}\text { B } \\
\text { B }\end{array}$ & $\begin{array}{l}\mathrm{D} \\
\mathrm{D}\end{array}$ & $\begin{array}{l}\mathrm{D} \\
\mathrm{D}\end{array}$ & $\begin{array}{l}\mathrm{A} \\
\mathrm{D} \\
\mathrm{D}\end{array}$ & $\begin{array}{l}\text { B } \\
\text { B }\end{array}$ & $\begin{array}{l}\mathrm{D} \\
\mathrm{D}\end{array}$ & $\begin{array}{l}\text { B } \\
\text { B }\end{array}$ & $\begin{array}{l}\text { B } \\
\text { B }\end{array}$ & $\begin{array}{l}\mathrm{B} \\
\mathrm{B}\end{array}$ & $\begin{array}{l}\mathrm{D} \\
\mathrm{D}\end{array}$ & $\begin{array}{l}\text { B } \\
\text { B }\end{array}$ & $\begin{array}{l}\mathrm{B} \\
\mathrm{B}\end{array}$ & $\begin{array}{l}\text { B } \\
\text { B }\end{array}$ & $\begin{array}{l}\text { B } \\
\text { B }\end{array}$ & $\begin{array}{l}\text { B } \\
\text { B }\end{array}$ & $\begin{array}{l}\mathrm{D} \\
\mathrm{D}\end{array}$ & $\begin{array}{l}\mathrm{D} \\
\mathrm{D}\end{array}$ & $\begin{array}{l}\text { B } \\
\text { B }\end{array}$ & $\begin{array}{l}D \\
D\end{array}$ & $\begin{array}{l}\mathrm{D} \\
\mathrm{D}\end{array}$ & $\begin{array}{l}226 \\
38\end{array}$ \\
\hline DIIMit4 & $\begin{array}{l}\mathbf{x} \\
-\end{array}$ & D & - & B & D & B & B & B & $\begin{array}{l}\mathrm{x} \\
\mathrm{B}\end{array}$ & D & $\begin{array}{l}\mathbf{x} \\
\mathbf{B}\end{array}$ & $\mathrm{B}$ & D & B & $\begin{array}{l}\mathbf{x} \\
\mathrm{D}\end{array}$ & B & D & B & B & B & B & B & D & $\mathrm{D}$ & - & x & - & 57 \\
\hline $\begin{array}{l}\text { Glut }-4 \\
\text { Glut-4 (mil) } \\
\text { Asgr-1 } \\
\text { Asgr-2 } \\
\text { Acrb } \\
\text { Atpb-2 } \\
\text { Atpb-2 } \\
\text { Zfp-3 }\end{array}$ & $\begin{array}{l}\mathrm{B} \\
\mathrm{B} \\
\mathrm{B} \\
\bar{B} \\
\mathrm{~B} \\
\mathrm{~B}\end{array}$ & $\begin{array}{l}D \\
D \\
D \\
D \\
D \\
D \\
D \\
D\end{array}$ & $\begin{array}{l}= \\
- \\
- \\
- \\
- \\
-\end{array}$ & $\begin{array}{l}\text { B } \\
\text { B } \\
\text { B } \\
\text { B } \\
\text { B } \\
\text { B } \\
\text { B } \\
\text { B }\end{array}$ & $\begin{array}{l}\text { D } \\
\text { D } \\
\text { D } \\
\text { D } \\
\text { D } \\
\text { D } \\
\text { D } \\
\text { D }\end{array}$ & $\begin{array}{l}\text { B } \\
\text { B } \\
\text { B } \\
\text { B } \\
\text { B } \\
\text { B } \\
\text { B } \\
\text { B }\end{array}$ & $\begin{array}{l}\text { B } \\
\text { B } \\
\text { B } \\
\text { B } \\
\text { B } \\
\text { B } \\
\text { B } \\
\text { B }\end{array}$ & $\begin{array}{l}\text { B } \\
\text { B } \\
\text { B } \\
\text { B } \\
\text { B } \\
\text { B } \\
\text { B } \\
\text { B }\end{array}$ & $\begin{array}{l}\text { B } \\
\text { B } \\
\text { B } \\
\text { B } \\
\text { B } \\
\text { B } \\
\text { B } \\
\text { B }\end{array}$ & $\begin{array}{l}\mathrm{D} \\
\mathrm{D} \\
\mathrm{D} \\
\mathrm{D} \\
\mathrm{D} \\
\mathrm{D} \\
\mathrm{D} \\
\mathrm{D}\end{array}$ & $\begin{array}{l}\text { B } \\
\text { B } \\
\text { B } \\
\text { B } \\
\text { B } \\
\text { B } \\
\text { B } \\
\text { B }\end{array}$ & $\begin{array}{l}\text { D } \\
\text { D } \\
\text { D } \\
\text { D } \\
\text { D } \\
\text { D } \\
\text { D } \\
D\end{array}$ & $\begin{array}{l}\text { D } \\
D \\
D \\
D \\
D \\
D \\
D \\
D\end{array}$ & $\begin{array}{l}\text { B } \\
\text { B } \\
\text { B } \\
\text { B } \\
\text { B } \\
\text { B } \\
\text { B } \\
\text { B }\end{array}$ & $\begin{array}{l}D \\
D \\
D \\
D \\
D \\
D \\
D \\
D\end{array}$ & $\begin{array}{l}\text { B } \\
-\bar{B} \\
\text { B } \\
\text { B } \\
\text { B } \\
\text { B } \\
\text { B }\end{array}$ & $\begin{array}{l}D \\
D \\
D \\
D \\
D \\
D \\
D \\
D\end{array}$ & $\begin{array}{l}\text { B } \\
\text { B } \\
\text { B } \\
\text { B } \\
\text { B } \\
\text { B } \\
\text { B } \\
\text { B }\end{array}$ & $\begin{array}{l}\text { B } \\
\text { B } \\
\text { B } \\
\text { B } \\
\text { B } \\
\text { B } \\
\text { B } \\
\text { B }\end{array}$ & $\begin{array}{l}\text { B } \\
\text { B } \\
\text { B } \\
\text { B } \\
\text { B } \\
\text { B } \\
\text { B } \\
\text { B }\end{array}$ & $\begin{array}{l}\text { B } \\
\text { B } \\
\text { B } \\
\text { B } \\
\text { B } \\
\text { B } \\
\text { B }\end{array}$ & $\begin{array}{l}\text { B } \\
\text { B } \\
\text { B } \\
\text { B } \\
\text { B } \\
\text { B } \\
\text { B } \\
\text { B }\end{array}$ & $\begin{array}{l}\text { D } \\
\text { D } \\
\text { D } \\
\text { D } \\
\text { D } \\
\text { D } \\
\text { D } \\
\text { D }\end{array}$ & $\begin{array}{l}\text { D } \\
\text { D } \\
\text { D } \\
\text { D } \\
D \\
D \\
D \\
D\end{array}$ & $\begin{array}{l}\text { B } \\
\overline{\text { B }} \\
\mathbf{B} \\
\mathbf{B} \\
\mathbf{B} \\
\mathbf{B} \\
\mathbf{B}\end{array}$ & $\begin{array}{l}\mathrm{B} \\
\bar{B} \\
\mathrm{~B} \\
\mathrm{~B} \\
\mathrm{~B} \\
\mathrm{~B} \\
\mathrm{~B} \\
\mathrm{~B}\end{array}$ & $\begin{array}{l}\mathrm{D} \\
- \\
- \\
- \\
\mathrm{D} \\
\mathrm{D} \\
\mathrm{D} \\
\mathrm{D}\end{array}$ & $\begin{array}{l}90 \\
57 \\
190 \\
190 \\
90 \\
136 \\
100 \\
7\end{array}$ \\
\hline DHINdsi & B & $\mathrm{D}$ & - & B & D & B & $\mathbf{B}$ & B & B & $\mathrm{D}$ & $B$ & $\mathrm{D}$ & D & - & $\mathrm{D}$ & B & $D$ & $\mathrm{~B}$ & $B$ & B & B & B & B & D & B & B & $\mathrm{D}$ & 41 \\
\hline $\begin{array}{l}M_{B p m-8} p-2 \\
B p\end{array}$ & $\begin{array}{l}\mathrm{B} \\
\mathrm{B}\end{array}$ & $\begin{array}{l}\mathrm{D} \\
\mathrm{D}\end{array}$ & - & $\begin{array}{l}\text { B } \\
\text { B }\end{array}$ & $\begin{array}{l}\mathrm{D} \\
\mathrm{D}\end{array}$ & $\begin{array}{l}\text { B } \\
\text { B }\end{array}$ & $\begin{array}{l}B \\
B\end{array}$ & $\begin{array}{l}\text { B } \\
\text { B }\end{array}$ & $\begin{array}{l}B \\
B\end{array}$ & $\begin{array}{l}\mathrm{D} \\
\mathrm{D}\end{array}$ & $\begin{array}{l}\hat{D} \\
\mathrm{D}\end{array}$ & $\begin{array}{l}\mathrm{D} \\
\mathrm{D}\end{array}$ & $\begin{array}{l}\mathrm{D} \\
\mathrm{D}\end{array}$ & $\begin{array}{l}\text { B } \\
\text { B }\end{array}$ & $\begin{array}{l}\mathrm{D} \\
-\end{array}$ & $\begin{array}{l}\text { B } \\
-\end{array}$ & $\begin{array}{l}\mathrm{D} \\
-\end{array}$ & B & $\begin{array}{l}\text { B } \\
-\end{array}$ & $\begin{array}{l}\mathrm{B} \\
\mathrm{B}\end{array}$ & $\begin{array}{l}B \\
-\end{array}$ & B & $\begin{array}{l}\text { B } \\
\text { B }\end{array}$ & $\begin{array}{l}\mathrm{D} \\
\mathrm{D}\end{array}$ & $\begin{array}{l}\text { B } \\
\text { B }\end{array}$ & B & $\begin{array}{l}\mathrm{D} \\
\mathrm{D}\end{array}$ & $\begin{array}{l}73 \\
77\end{array}$ \\
\hline $\begin{array}{l}\text { Tca-3 } \\
X m m v-3 \\
\text { Mpmv-4 } \\
X m v-42 \\
\text { Mpo } \\
\text { Mipla } \\
\text { Miplb }\end{array}$ & $\begin{array}{l}\text { B } \\
\text { B } \\
\text { B } \\
\text { B } \\
\\
\text { B } \\
\text { B }\end{array}$ & $\begin{array}{l}D \\
D \\
D \\
D \\
D \\
D \\
D\end{array}$ & $\begin{array}{l}- \\
- \\
- \\
- \\
- \\
-\end{array}$ & $\begin{array}{l}\mathrm{X} \\
\mathrm{D} \\
\mathrm{D} \\
\mathrm{D} \\
\mathrm{D} \\
\mathrm{D} \\
\mathrm{D} \\
\mathrm{D}\end{array}$ & $\begin{array}{l}\mathrm{X} \\
\mathrm{B} \\
\mathrm{B} \\
\mathrm{B} \\
\mathrm{B} \\
\mathrm{B} \\
\mathrm{B} \\
\mathrm{B} \\
\mathrm{B}\end{array}$ & $\begin{array}{l}\text { B } \\
\text { B } \\
\text { B } \\
\text { B } \\
\text { B } \\
\text { B } \\
\text { B }\end{array}$ & $\begin{array}{l}\mathrm{X} \\
\mathrm{D} \\
\mathrm{D} \\
\mathrm{D} \\
\mathrm{D} \\
\mathrm{D} \\
\mathrm{D} \\
\mathrm{D}\end{array}$ & $\begin{array}{l}\text { B } \\
\text { B } \\
\text { B } \\
\text { B } \\
\text { B } \\
\text { B } \\
\text { B }\end{array}$ & $\begin{array}{l}\text { D } \\
\mathrm{D} \\
\mathrm{D} \\
\mathrm{D} \\
\mathrm{D} \\
\mathrm{D} \\
\mathrm{D} \\
\mathrm{D}\end{array}$ & $\begin{array}{l}\mathbf{B} \\
\mathbf{B} \\
\mathbf{B} \\
\mathbf{B} \\
\mathbf{B} \\
\mathbf{B} \\
\mathbf{B}\end{array}$ & $\begin{array}{l}D \\
D \\
D \\
D \\
D \\
D \\
D\end{array}$ & $\begin{array}{l}D \\
D \\
D \\
D \\
- \\
D \\
D\end{array}$ & $\begin{array}{l}\mathrm{D} \\
\mathrm{D} \\
\mathrm{D} \\
\mathrm{D} \\
\mathrm{D} \\
\mathrm{D} \\
\mathrm{D}\end{array}$ & $\begin{array}{l}\text { B } \\
\mathbf{B} \\
\mathbf{B} \\
\mathbf{B} \\
\mathbf{B} \\
\mathbf{B} \\
\mathbf{B}\end{array}$ & $\begin{array}{l}D \\
D \\
D \\
D \\
D \\
D \\
D\end{array}$ & $\begin{array}{l}\mathrm{D} \\
\mathrm{D} \\
\mathrm{D} \\
\mathrm{D} \\
\mathrm{D} \\
\mathrm{D} \\
\mathrm{D}\end{array}$ & $\begin{array}{l}D \\
D \\
D \\
D \\
D \\
D \\
D\end{array}$ & $\begin{array}{l}\mathrm{X} \\
\mathrm{D} \\
\mathrm{D} \\
\mathrm{D} \\
\mathrm{D} \\
\mathrm{D} \\
\mathrm{D} \\
\mathrm{D}\end{array}$ & $\begin{array}{l}\text { B } \\
\text { B } \\
\text { B } \\
\text { B } \\
\text { B } \\
\text { B } \\
\text { B }\end{array}$ & $\begin{array}{l}\text { B } \\
\text { B } \\
\text { B } \\
\text { B } \\
\text { B } \\
\text { B } \\
\text { B }\end{array}$ & $\begin{array}{l}\text { B } \\
\text { B } \\
\text { B } \\
\text { B } \\
\text { B } \\
\text { B } \\
\text { B }\end{array}$ & $\begin{array}{l}\text { B } \\
\text { B } \\
\text { B } \\
\text { B } \\
\text { B } \\
\text { B } \\
\text { B }\end{array}$ & $\begin{array}{l}\mathrm{B} \\
\mathrm{B} \\
\mathrm{B} \\
\mathrm{B} \\
\mathrm{B} \\
\mathrm{B} \\
\mathrm{B}\end{array}$ & $\begin{array}{l}\text { D } \\
\text { D } \\
\text { D } \\
D \\
D \\
D \\
D\end{array}$ & $\begin{array}{l}\text { B } \\
\text { B } \\
\text { B } \\
\text { B } \\
\text { B } \\
\text { B } \\
\text { B }\end{array}$ & $\begin{array}{l}\text { B } \\
\text { B } \\
\text { B } \\
\text { B } \\
\text { B } \\
\text { B } \\
\text { B }\end{array}$ & $\begin{array}{l}D \\
D \\
D \\
D \\
D \\
D \\
D\end{array}$ & $\begin{array}{l}226 \\
21 \\
73 \\
71 \\
90 \\
226 \\
226\end{array}$ \\
\hline AntP9la & - & $\mathrm{D}$ & - & D & $\stackrel{x}{D}$ & $\stackrel{\mathrm{x}}{\mathrm{D}}$ & $\mathrm{D}$ & B & $\begin{array}{l}x \\
B\end{array}$ & B & D & $\mathrm{D}$ & $\mathrm{D}$ & B & D & D & D & D & B & $\begin{array}{l}\mathrm{x} \\
\mathrm{D}\end{array}$ & B & B & B & D & - & - & - & 57 \\
\hline Hox -2 & B & $\mathrm{D}$ & - & D & D & D & $\mathrm{D}$ & B & B & B & D & $\mathrm{D}$ & $\mathrm{D}$ & B & D & $\mathrm{D}$ & $\mathrm{D}$ & $\mathrm{D}$ & B & D & B & $\stackrel{A}{D}$ & B & D & $\begin{array}{l}X \\
\mathrm{D}\end{array}$ & B & D & 131 \\
\hline${ }_{K r t-1}^{K r+1} C B$ & $\mathbf{B}$ & $\begin{array}{l}D \\
D\end{array}$ & - & $\begin{array}{l}\mathrm{D} \\
\mathrm{D}\end{array}$ & $\bar{D}$ & $\begin{array}{l}\mathrm{D} \\
\mathrm{D}\end{array}$ & $\begin{array}{l}\mathrm{D} \\
\mathrm{D}\end{array}$ & $\begin{array}{l}\text { B } \\
\text { B }\end{array}$ & $\begin{array}{l}\mathrm{B} \\
\mathrm{B}\end{array}$ & $\begin{array}{l}\mathrm{B} \\
\mathrm{B}\end{array}$ & $\begin{array}{l}\text { D } \\
\text { D }\end{array}$ & $\begin{array}{l}\mathrm{D} \\
\mathrm{D}\end{array}$ & $\begin{array}{l}\mathrm{D} \\
\mathrm{D}\end{array}$ & $\begin{array}{l}\text { B } \\
\text { B }\end{array}$ & $\begin{array}{l}\mathrm{D} \\
\mathrm{D}\end{array}$ & $\begin{array}{l}\mathrm{D} \\
\mathrm{D}\end{array}$ & $\begin{array}{l}\mathrm{D} \\
\mathrm{D}\end{array}$ & $\begin{array}{l}\mathrm{D} \\
\mathrm{D}\end{array}$ & $\begin{array}{l}\mathrm{B} \\
\mathrm{B}\end{array}$ & $\begin{array}{l}\mathrm{D} \\
\mathrm{D}\end{array}$ & $\begin{array}{l}\mathrm{B} \\
\mathrm{B}\end{array}$ & $\begin{array}{l}\mathrm{A} \\
\mathrm{B}\end{array}$ & $\begin{array}{l}\mathrm{B} \\
\mathrm{B}\end{array}$ & $\begin{array}{l}\text { B } \\
\text { B }\end{array}$ & $\begin{array}{l}\mathrm{D} \\
\mathrm{D}\end{array}$ & $\begin{array}{l}\text { B } \\
\text { B }\end{array}$ & $\begin{array}{l}\mathrm{D} \\
\mathrm{D}\end{array}$ & $\begin{array}{l}150 \\
163\end{array}$ \\
\hline $\begin{array}{l}\text { DllNds2 } \\
\text { Gfap } \\
\text { Gfap } T T\end{array}$ & $\begin{array}{l}\mathrm{D} \\
\mathrm{D} \\
\mathrm{D}\end{array}$ & $\begin{array}{l}\mathrm{D} \\
\mathrm{D} \\
\mathrm{D}\end{array}$ & $\begin{array}{l}- \\
-\end{array}$ & $\begin{array}{l}\mathrm{D} \\
\mathrm{D} \\
\mathrm{D}\end{array}$ & $\begin{array}{l}\mathrm{D} \\
\overline{\mathrm{D}}\end{array}$ & $\begin{array}{l}\mathrm{D} \\
\mathrm{D}\end{array}$ & $\begin{array}{l}\mathrm{D} \\
\mathrm{D} \\
\mathrm{D}\end{array}$ & $\begin{array}{l}\text { B } \\
\text { B } \\
\text { B }\end{array}$ & $\begin{array}{l}\mathrm{B} \\
\mathrm{B} \\
\mathrm{B}\end{array}$ & $\begin{array}{l}\text { B } \\
\text { B } \\
\text { B }\end{array}$ & $\begin{array}{l}\mathrm{D} \\
\mathrm{D} \\
\mathrm{D}\end{array}$ & $\begin{array}{l}\mathrm{D} \\
\mathrm{D} \\
\mathrm{D}\end{array}$ & $\begin{array}{l}\text { B } \\
B \\
B \\
B\end{array}$ & $\begin{array}{l}\mathrm{A} \\
\mathrm{D} \\
\mathrm{D}\end{array}$ & $\begin{array}{l}\mathrm{D} \\
\mathrm{D} \\
\mathrm{D}\end{array}$ & $\begin{array}{l}\mathrm{D} \\
\overline{\mathrm{D}}\end{array}$ & $\begin{array}{l}\mathrm{D} \\
\overline{\mathrm{D}}\end{array}$ & $\begin{array}{l}\mathrm{D} \\
\mathrm{D} \\
\mathrm{D}\end{array}$ & $\begin{array}{l}\text { B } \\
\text { B } \\
\text { B }\end{array}$ & $\begin{array}{l}\mathrm{D} \\
\mathrm{D} \\
\mathrm{D}\end{array}$ & $\begin{array}{l}\text { B } \\
\text { B } \\
\text { B }\end{array}$ & $\begin{array}{l}\text { B } \\
\text { B } \\
\text { B }\end{array}$ & $\begin{array}{l}\mathrm{B} \\
\mathrm{B} \\
\mathrm{B}\end{array}$ & $\begin{array}{l}\text { B } \\
\text { B } \\
\text { B }\end{array}$ & $\begin{array}{l}\mathrm{D} \\
\mathrm{D} \\
\mathrm{D}\end{array}$ & $\begin{array}{l}\mathrm{B} \\
\mathrm{B} \\
\mathrm{B}\end{array}$ & $\begin{array}{l}\mathrm{D} \\
\mathrm{D} \\
\mathrm{D}\end{array}$ & $\begin{array}{l}90 \\
18 \\
131\end{array}$ \\
\hline$E m p b 3$ & D & D & - & D & D & - & $\mathrm{D}$ & B & B & B & B & D & B & D & D & D & D & D & B & D & B & B & B & B & D & B & D & 131 \\
\hline Myla & $\mathrm{D}$ & D & - & $\mathrm{D}$ & D & D & D & B & B & B & B & B & B & D & D & D & D & D & B & D & B & B & B & B & D & B & D & 131 \\
\hline$M p m \nu-8$ & $\mathrm{D}$ & D & - & $\begin{array}{l}\mathrm{D} \\
\mathrm{x}\end{array}$ & D & D & $\mathrm{D}$ & $\hat{\mathrm{D}}$ & $\hat{\mathrm{D}}$ & $\hat{\mathrm{D}}$ & $\hat{\mathrm{D}}$ & $\mathrm{D}$ & $\begin{array}{l}B \\
x\end{array}$ & $\begin{array}{l}\mathrm{D} \\
\mathrm{x}\end{array}$ & $\mathrm{D}$ & D & $\mathrm{D}$ & D & B & D & B & $B$ & B & B & $\mathrm{D}$ & B & D & 73 \\
\hline $\begin{array}{l}E s-3 \\
D 11 J k n \\
T k-1\end{array}$ & $\begin{array}{l}\text { D } \\
\text { D } \\
\text { D }\end{array}$ & $\begin{array}{l}\mathrm{D} \\
\mathrm{D} \\
\mathrm{D}\end{array}$ & $\begin{array}{l}\text { D } \\
- \\
-\end{array}$ & $\begin{array}{l}B \\
B \\
B\end{array}$ & $\begin{array}{l}\mathrm{D} \\
\mathrm{D} \\
\mathrm{D}\end{array}$ & $\begin{array}{l}\mathrm{D} \\
\mathrm{D} \\
\mathrm{D}\end{array}$ & $\begin{array}{l}\mathrm{D} \\
\mathrm{D} \\
\mathrm{D}\end{array}$ & $\begin{array}{l}\text { B } \\
\text { B } \\
\text { B }\end{array}$ & $\begin{array}{l}\mathrm{D} \\
\mathrm{D} \\
\mathrm{D}\end{array}$ & $\begin{array}{l}\mathrm{D} \\
-\mathrm{D}\end{array}$ & $\begin{array}{l}\text { B } \\
\text { B } \\
\text { B }\end{array}$ & $\begin{array}{l}D \\
D \\
D\end{array}$ & $\begin{array}{l}\mathrm{D} \\
\mathrm{D} \\
\mathrm{D}\end{array}$ & $\begin{array}{l}\text { B } \\
\text { B } \\
\text { B }\end{array}$ & $\begin{array}{l}\text { B } \\
\text { B } \\
\text { B }\end{array}$ & $\begin{array}{l}\mathrm{D} \\
\frac{\mathrm{D}}{}\end{array}$ & $\begin{array}{l}\mathrm{D} \\
-\mathrm{D}\end{array}$ & $\begin{array}{l}\mathrm{D} \\
\mathrm{D} \\
\mathrm{D}\end{array}$ & $\begin{array}{l}B \\
\bar{B}\end{array}$ & $\begin{array}{l}D \\
D \\
D\end{array}$ & $\begin{array}{l}\mathrm{D} \\
\mathrm{D} \\
\mathrm{D}\end{array}$ & $\frac{\mathrm{D}}{\mathrm{D}}$ & $\begin{array}{l}\mathbf{B} \\
\mathbf{B} \\
\mathbf{B}\end{array}$ & $\begin{array}{l}\mathrm{B} \\
\mathrm{B} \\
\mathrm{B}\end{array}$ & $\begin{array}{l}\mathrm{D} \\
\mathrm{D} \\
\mathrm{D}\end{array}$ & $\begin{array}{l}\mathrm{B} \\
\bar{B}\end{array}$ & $\begin{array}{l}\mathrm{D} \\
\mathrm{D} \\
\mathrm{D}\end{array}$ & $\begin{array}{l}211 \\
107 \\
138\end{array}$ \\
\hline Gam & D & D & - & B & $\mathrm{D}$ & D & $\mathrm{D}$ & B & D & D & B & D & $\mathrm{D}$ & B & B & D & D & D & B & B & D & D & $\mathrm{B}$ & B & $\mathrm{D}$ & B & D & 138 \\
\hline
\end{tabular}

Table 4. Continued. SDPs of Chr 11 loci typed in AKXL RI strains. A and L represent alleles derived from AKR/J and C57L/J, respectively.

\begin{tabular}{|c|c|c|c|c|c|c|c|c|c|c|c|c|c|c|c|c|c|c|c|c|c|c|c|c|c|c|}
\hline $\begin{array}{l}\text { Locus } \\
P_{m v-22} \\
P m v-2\end{array}$ & $\begin{array}{l}\frac{1}{-} \\
-\end{array}$ & $\begin{array}{l}2 \\
- \\
-\end{array}$ & $\begin{array}{l}4 \\
- \\
-\end{array}$ & $\begin{array}{l}5 \\
A \\
-\end{array}$ & $\begin{array}{l}6 \\
L \\
L\end{array}$ & $\begin{array}{l}7 \\
A \\
A\end{array}$ & $\begin{array}{l}8 \\
\bar{L} \\
\mathrm{~L}\end{array}$ & $\begin{array}{l}9 \\
\mathrm{~A} \\
\mathrm{~A}\end{array}$ & $\begin{array}{l}11 \\
- \\
-\end{array}$ & $\begin{array}{l}12 \\
\mathrm{~L} \\
\mathrm{~L}\end{array}$ & $\begin{array}{l}13 \\
\mathrm{~L} \\
\mathrm{~L}\end{array}$ & $\begin{array}{l}14 \\
\mathrm{~A} \\
\mathrm{~A}\end{array}$ & $\begin{array}{l}16 \\
\mathrm{~A} \\
\mathrm{~A}\end{array}$ & $\begin{array}{l}17 \\
\mathrm{~A} \\
\mathrm{~A}\end{array}$ & $\begin{array}{l}18 \\
- \\
-\end{array}$ & $\begin{array}{l}19 \\
\mathrm{~L} \\
\mathrm{~L}\end{array}$ & $\begin{array}{l}21 \\
\mathrm{~A} \\
\mathrm{~A}\end{array}$ & $\begin{array}{l}23 \\
- \\
-\end{array}$ & $\begin{array}{l}24 \\
\mathrm{~L} \\
\mathrm{~L}\end{array}$ & $\begin{array}{l}25 \\
\mathrm{~A}\end{array}$ & $\begin{array}{l}28 \\
A \\
A\end{array}$ & $\begin{array}{l}29 \\
A \\
A\end{array}$ & $\begin{array}{l}36 \\
- \\
-\end{array}$ & $\frac{37}{\mathrm{~A}}$ & $\begin{array}{l}38 \\
A \\
A\end{array}$ & $\begin{array}{l}\text { Reference } \\
72 \\
72\end{array}$ \\
\hline Erbb & - & - & - & A & $\mathrm{L}$ & $\begin{array}{l}x \\
L\end{array}$ & $\mathrm{~L}$ & A & - & $\mathrm{L}$ & $\mathrm{L}$ & A & A & A & - & $\mathrm{L}$ & A & - & $\mathrm{L}$ & A & $\begin{array}{l}A \\
x\end{array}$ & A & - & $\begin{array}{l}\mathrm{X} \\
\mathrm{L}\end{array}$ & A & 199 \\
\hline$M p m v-18$ & - & - & - & $\mathrm{A}$ & $\mathrm{L}$ & $\mathrm{L}$ & $\mathrm{L}$ & A & - & $\mathbf{L}$ & $\hat{\mathrm{A}}$ & $\mathrm{A}$ & A & A & - & $\mathrm{L}$ & $\hat{\mathrm{L}}$ & - & $\mathrm{L}$ & A & $\hat{\mathrm{L}}$ & $A$ & - & A & A & 73 \\
\hline$H b a$ & - & - & - & A & $\mathbf{L}$ & - & $\mathrm{L}$ & $A$ & - & $\mathbf{L}$ & A & A & A & A & - & L & $\mathrm{L}$ & - & $\mathrm{L}$ & A & $\mathrm{L}$ & $\hat{\mathrm{L}}$ & - & $\hat{\mathrm{L}}$ & A & 199 \\
\hline$E m v-14$ & - & - & - & A & $\mathbf{x}$ & $\begin{array}{l}x \\
A\end{array}$ & $\mathrm{X}$ & $\begin{array}{l}\mathrm{x} \\
\mathrm{L}\end{array}$ & - & $\mathbf{L}$ & $A$ & A & $\begin{array}{l}X \\
\mathrm{~L}\end{array}$ & A & - & $\stackrel{x}{A}$ & $\mathrm{~L}$ & - & $\mathrm{A}$ & $\begin{array}{l}x \\
L\end{array}$ & $\mathrm{~L}$ & $\mathrm{~L}$ & $\mathbf{L}$ & $\hat{\mathrm{A}}$ & A & 213 \\
\hline $\begin{array}{l}\text { Evi-2 } \\
\text { Mpmv-2 }\end{array}$ & - & - & - & $\mathrm{A}$ & $\begin{array}{l}\mathrm{A} \\
\mathrm{A}\end{array}$ & A & $\begin{array}{l}\mathrm{A} \\
\mathrm{A}\end{array}$ & $\begin{array}{l}\mathrm{L} \\
\mathrm{L}\end{array}$ & - & $\begin{array}{l}\mathbf{L} \\
\mathbf{L}\end{array}$ & $\begin{array}{l}\mathrm{L} \\
\mathrm{L}\end{array}$ & $\begin{array}{l}A \\
A\end{array}$ & $\begin{array}{l}\mathrm{L} \\
\mathrm{L}\end{array}$ & $\stackrel{\mathrm{A}}{\mathrm{A}}$ & $\overline{-}$ & $\stackrel{A}{A}$ & $\begin{array}{l}\mathrm{L} \\
\mathrm{L}\end{array}$ & - & $\mathrm{A}$ & $\begin{array}{l}\mathrm{L} \\
\mathrm{L}\end{array}$ & $\begin{array}{l}\mathrm{L} \\
\mathrm{L}\end{array}$ & A & - & $\mathrm{A}$ & $\stackrel{A}{A}$ & $\begin{array}{l}26 \\
73\end{array}$ \\
\hline$T c a-3$ & - & - & - & A & A & A & A & $\mathrm{L}$ & - & $\mathbf{L}$ & $\mathrm{L}$ & A & $L$ & A & - & A & $\mathrm{L}$ & - & A & $\mathrm{L}$ & L & $\hat{\mathrm{L}}$ & - & A & A & 226 \\
\hline $\begin{array}{l}\text { Mpmv-4 } \\
\text { Mipla } \\
\text { Miplb }\end{array}$ & $\begin{array}{l}- \\
-\end{array}$ & $\begin{array}{l}- \\
-\end{array}$ & $\begin{array}{l}- \\
-\end{array}$ & $\begin{array}{l}\bar{A} \\
\mathbf{A}\end{array}$ & $\begin{array}{l}\mathrm{A} \\
\mathrm{A} \\
\mathrm{A}\end{array}$ & $\begin{array}{l}\mathrm{A} \\
\mathrm{A} \\
\mathrm{A}\end{array}$ & $\begin{array}{l}\mathrm{A} \\
\mathrm{A} \\
\mathbf{A}\end{array}$ & $\begin{array}{l}\mathrm{L} \\
\mathrm{L} \\
\mathrm{L}\end{array}$ & $\begin{array}{l}- \\
-\end{array}$ & $\begin{array}{l}\mathrm{L} \\
\mathrm{L} \\
\mathrm{L}\end{array}$ & $\begin{array}{l}\mathrm{L} \\
\mathrm{L} \\
\mathrm{L}\end{array}$ & $\begin{array}{l}\text { A } \\
\text { A } \\
\text { A }\end{array}$ & $\begin{array}{l}\mathrm{A} \\
\mathrm{A} \\
\mathrm{A}\end{array}$ & $\begin{array}{l}\mathrm{A} \\
\mathrm{A} \\
\mathrm{A}\end{array}$ & $\begin{array}{l}- \\
- \\
-\end{array}$ & $\begin{array}{l}\mathrm{A} \\
\mathrm{A} \\
\mathrm{A}\end{array}$ & $\begin{array}{l}\mathrm{L} \\
\mathrm{L} \\
\mathrm{L}\end{array}$ & $\begin{array}{l}- \\
- \\
-\end{array}$ & $\begin{array}{l}\mathrm{A} \\
\mathrm{A} \\
\mathrm{A}\end{array}$ & $\begin{array}{l}\mathrm{L} \\
\mathrm{L} \\
\mathrm{L}\end{array}$ & $\begin{array}{l}\text { L } \\
\text { L } \\
\text { L }\end{array}$ & $\begin{array}{l}\text { L } \\
\text { L } \\
\text { L }\end{array}$ & $\begin{array}{l}- \\
- \\
-\end{array}$ & $\begin{array}{l}\mathrm{A} \\
\mathrm{A} \\
\mathrm{A}\end{array}$ & $\begin{array}{l}\mathrm{A} \\
\mathrm{A} \\
\mathrm{A}\end{array}$ & $\begin{array}{l}73 \\
226 \\
226\end{array}$ \\
\hline$X m v-42$ & - & - & - & A & A & A & A & $\mathbf{L}$ & - & L & L & A & A & A & - & A & $\mathrm{L}$ & - & $\hat{\mathrm{L}}$ & $\mathrm{L}$ & $\mathrm{L}$ & $\mathrm{L}$ & - & $\mathrm{A}$ & A & 71 \\
\hline$X m v-20$ & - & - & - & A & A & A & A & $\mathbf{L}$ & - & L & $\mathbf{L}$ & A & A & A & - & A & L & - & L & L & $\mathrm{A}$ & A & - & $\mathrm{A}$ & A & 71 \\
\hline Hox-2 & - & - & - & A & A & A & A & $\mathbf{L}$ & - & $\mathbf{L}$ & $\mathbf{L}$ & A & A & A & - & $\hat{\mathrm{L}}$ & $\mathrm{L}$ & - & $\mathbf{L}$ & $\mathrm{L}$ & $\mathrm{L}$ & A & - & $\mathrm{A}$ & A & 89 \\
\hline$C_{n p-1}$ & - & - & - & A & $\mathrm{A}$ & A & A & $\mathbf{L}$ & - & $\mathbf{L}$ & $\mathrm{L}$ & A & $\begin{array}{l}\mathrm{K} \\
\mathrm{L}\end{array}$ & $\mathrm{A}$ & - & $\mathrm{L}$ & $\mathrm{L}$ & - & $\mathrm{L}$ & A & $\mathrm{L}$ & $\mathrm{L}$ & - & $\mathrm{A}$ & A & 18 \\
\hline Mpmv-8 & - & - & - & A & A & $\begin{array}{l}\mathrm{x} \\
\mathrm{L}\end{array}$ & $\hat{\mathrm{L}}$ & $\mathrm{L}$ & - & $\mathbf{L}$ & $\mathbf{L}$ & A & $\mathrm{L}$ & A & - & $\mathrm{L}$ & L & - & $\mathbf{L}$ & A & L & L & - & A & $\begin{array}{l}x \\
L\end{array}$ & 73 \\
\hline$E s-3$ & $\mathbf{L}$ & A & $\mathrm{A}$ & A & $\mathbf{L}$ & $\mathrm{L}$ & $\hat{A}$ & $\mathrm{~L}$ & L & $\mathbf{L}$ & $\mathrm{L}$ & $\hat{\mathrm{L}}$ & $\mathrm{L}$ & A & $\mathrm{A}$ & $\hat{A}$ & $\mathrm{~L}$ & A & $\mathbf{L}$ & $\hat{\mathrm{L}}$ & $\mathrm{L}$ & L & L & A & $\hat{A}$ & 153 \\
\hline Gea & - & - & - & A & L & $\mathrm{L}$ & A & L & - & L & $\mathrm{L}$ & L & $\mathrm{L}$ & A & - & A & $\mathrm{L}$ & - & $\mathbf{L}$ & $\mathrm{L}$ & - & - & - & $\mathrm{A}$ & $\hat{\mathrm{L}}$ & 138 \\
\hline Glk & - & - & - & $\mathrm{A}$ & $\mathbf{L}$ & $\hat{A}$ & A & $\mathrm{L}$ & - & - & $\hat{A}$ & L & $\mathrm{L}$ & $\mathrm{A}$ & - & $A$ & $\mathrm{~L}$ & - & $\mathbf{L}$ & $\mathrm{L}$ & L & L & - & A & L & 153 \\
\hline Mpmv-15 & - & - & - & A & L & $\begin{array}{l}\mathbf{x} \\
\mathbf{L}\end{array}$ & A & $\mathrm{L}$ & - & - & A & L & $\mathrm{L}$ & A & - & A & L & - & $\mathrm{A}$ & L & $\mathrm{L}$ & L & - & A & $\mathrm{L}$ & 73 \\
\hline
\end{tabular}


Table 4. Continued. SDPs of Chr 11 loci typed in BXH RI strains. B and $\mathrm{H}$ represent alleles derived from C57BL/6J and C3H/HeJ, respectively.

\begin{tabular}{|c|c|c|c|c|c|c|c|c|c|c|c|c|c|c|c|c|c|}
\hline $\begin{array}{l}\text { Locus } \\
P m v-22 \\
P m v-2\end{array}$ & $\begin{array}{l}2 \\
\mathrm{H} \\
\mathrm{H}\end{array}$ & $\begin{array}{l}3 \\
H \\
H\end{array}$ & $\begin{array}{l}4 \\
H \\
H\end{array}$ & $\begin{array}{l}5 \\
- \\
-\end{array}$ & $\begin{array}{l}6 \\
H \\
H\end{array}$ & $\begin{array}{l} \\
B \\
B\end{array}$ & $\begin{array}{l}8 \\
B \\
B\end{array}$ & $\begin{array}{l}9 \\
B \\
B\end{array}$ & $\frac{10}{\mathrm{~B}}$ & $\begin{array}{l}11 \\
\mathrm{H} \\
\mathrm{H}\end{array}$ & $\begin{array}{l}12 \\
B \\
B\end{array}$ & $\begin{array}{l}14 \\
\mathrm{H} \\
\mathrm{H}\end{array}$ & $\begin{array}{l}15 \\
- \\
-\end{array}$ & $\begin{array}{l}18 \\
- \\
-\end{array}$ & $\begin{array}{l}9 \\
\mathrm{H} \\
\mathrm{H}\end{array}$ & $\begin{array}{l}20 \\
- \\
-\end{array}$ & $\begin{array}{l}\text { Reference } \\
72 \\
72\end{array}$ \\
\hline$H b a$ & $\begin{array}{l}\mathbf{x} \\
\mathbf{B}\end{array}$ & $\mathrm{H}$ & $\begin{array}{l}X \\
B\end{array}$ & H & $\mathrm{H}$ & B & B & B & B & $\begin{array}{l}\mathrm{x} \\
\mathrm{B}\end{array}$ & B & $\mathrm{H}$ & - & B & $\mathrm{H}$ & B & 38 \\
\hline $\begin{array}{l}\text { Sparc } \\
\text { D4SlOh }\end{array}$ & $\begin{array}{l}B \\
B\end{array}$ & $\begin{array}{l}\mathrm{H} \\
\mathrm{H}\end{array}$ & $\begin{array}{l}\text { B } \\
\text { B }\end{array}$ & - & $\begin{array}{l}\mathrm{H} \\
\mathrm{H}\end{array}$ & $\begin{array}{l}\mathrm{X} \\
\mathrm{H} \\
\mathrm{H}\end{array}$ & $\begin{array}{l}\mathrm{X} \\
\mathrm{H} \\
\mathrm{H}\end{array}$ & $\begin{array}{l}\text { B } \\
\text { B }\end{array}$ & $\begin{array}{l}\mathrm{B} \\
\mathrm{B}\end{array}$ & $\begin{array}{l}\text { B } \\
\text { B }\end{array}$ & $\begin{array}{l}\text { B } \\
\text { B }\end{array}$ & $\begin{array}{l}\mathrm{X} \\
\mathrm{B} \\
\mathrm{B}\end{array}$ & 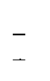 & - & $\overline{\mathrm{H}}$ & - & $\begin{array}{l}139 \\
38\end{array}$ \\
\hline$M p m v-2$ & $\mathrm{H}$ & H & B & - & $\mathrm{H}$ & $\mathbf{H}$ & $\mathbf{H}$ & B & $\mathrm{B}$ & $\mathrm{B}$ & $\stackrel{\mathbf{X}}{\mathbf{H}}$ & $\begin{array}{l}\mathrm{X} \\
\mathrm{H}\end{array}$ & - & - & $\begin{array}{l}X \\
B\end{array}$ & - & 73 \\
\hline Mpmv-4 & $\mathrm{H}$ & H & $\stackrel{\mathrm{A}}{\mathrm{H}}$ & - & $\mathrm{H}$ & $\mathbf{H}$ & $\mathrm{H}$ & B & $\mathrm{B}$ & B & $\mathbf{H}$ & $\mathrm{H}$ & - & - & B & - & 73 \\
\hline$X m v-42$ & $\mathrm{H}$ & $\mathbf{H}$ & $\mathrm{H}$ & - & $\mathrm{H}$ & $\mathbf{H}$ & $\mathbf{H}$ & $\mathrm{B}$ & $\mathrm{B}$ & $\mathrm{B}$ & $\hat{\mathrm{B}}$ & $\mathrm{H}$ & - & - & B & - & 71 \\
\hline $\begin{array}{l}\text { Krt-l } \\
\text { Gfap }\end{array}$ & $\begin{array}{l}\mathrm{B} \\
\mathrm{B}\end{array}$ & $\underset{H}{\mathrm{H}}$ & $\begin{array}{l}\mathrm{H} \\
\mathrm{H}\end{array}$ & $\overline{-}$ & $\begin{array}{l}\mathrm{H} \\
\mathrm{H}\end{array}$ & $\underset{\mathrm{H}}{\mathrm{H}}$ & $\begin{array}{l}\mathrm{H} \\
\mathrm{H}\end{array}$ & $\begin{array}{l}\text { B } \\
\text { B }\end{array}$ & $\begin{array}{l}\mathrm{B} \\
\mathrm{B}\end{array}$ & $\begin{array}{l}\mathrm{X} \\
\mathrm{H} \\
\mathrm{H}\end{array}$ & $\begin{array}{l}\text { B } \\
\text { B }\end{array}$ & $\underset{\mathrm{H}}{\mathrm{H}}$ & $\begin{array}{l}- \\
-\end{array}$ & - & $\begin{array}{l}\mathrm{B} \\
\mathrm{B}\end{array}$ & - & $\begin{array}{l}163 \\
18\end{array}$ \\
\hline $\begin{array}{l}\text { Myla } \\
\text { Mpmv-8 }\end{array}$ & $\overline{\mathrm{B}}$ & $\overrightarrow{\mathrm{H}}$ & $\begin{array}{l}\mathrm{H} \\
\mathrm{H}\end{array}$ & - & $\begin{array}{l}{ }_{B} \\
B \\
B\end{array}$ & $\begin{array}{l}\mathrm{H} \\
\mathrm{H}\end{array}$ & $\begin{array}{l}\mathrm{H} \\
\mathrm{H}\end{array}$ & $\begin{array}{l}\mathrm{B} \\
\mathrm{B}\end{array}$ & $\begin{array}{l}\mathrm{B} \\
\mathrm{B}\end{array}$ & $\begin{array}{l}\mathrm{H} \\
\mathrm{H}\end{array}$ & $\begin{array}{l}\text { B } \\
\text { B }\end{array}$ & $\begin{array}{l}\mathrm{H} \\
\mathrm{H}\end{array}$ & - & $\overline{-}$ & $\begin{array}{l}\text { B } \\
\text { B }\end{array}$ & $\overline{-}$ & $\begin{array}{l}183 \\
73\end{array}$ \\
\hline $\begin{array}{l}E s-3 \\
T k-1\end{array}$ & $\begin{array}{l}B \\
B\end{array}$ & $\begin{array}{l}X \\
\text { B } \\
B\end{array}$ & $\begin{array}{l}\mathrm{H} \\
\mathrm{H}\end{array}$ & $\underline{H}$ & $\begin{array}{l}\mathrm{B} \\
\mathrm{B}\end{array}$ & $\begin{array}{l}\mathbf{H} \\
\mathbf{H}\end{array}$ & $\begin{array}{l}\mathrm{H} \\
\mathrm{H}\end{array}$ & $\begin{array}{l}\mathrm{B} \\
\mathrm{B}\end{array}$ & $\begin{array}{l}\mathrm{B} \\
\mathrm{B}\end{array}$ & $\begin{array}{l}\mathrm{H} \\
\mathrm{H}\end{array}$ & $\begin{array}{l}\text { B } \\
\text { B }\end{array}$ & $\begin{array}{l}\mathrm{X} \\
\mathrm{B} \\
\mathrm{B}\end{array}$ & $\begin{array}{l}\text { B } \\
-\end{array}$ & $\begin{array}{l}\mathrm{B} \\
-\end{array}$ & $\begin{array}{l}\mathrm{B} \\
\mathrm{B}\end{array}$ & B & $\begin{array}{l}153 \\
138\end{array}$ \\
\hline Gaa & $\stackrel{A}{\mathrm{H}}$ & B & $\mathrm{H}$ & - & $\mathrm{B}$ & $\mathrm{H}$ & $\mathrm{H}$ & B & $\mathrm{B}$ & $\mathrm{H}$ & B & $\hat{\mathrm{H}}$ & - & - & B & - & 138 \\
\hline Glk & $\begin{array}{l}\mathrm{X} \\
\mathrm{B}\end{array}$ & B & $\mathrm{H}$ & H & B & $\mathrm{H}$ & $\mathrm{H}$ & B & B & $\mathrm{H}$ & B & $\mathrm{H}$ & - & B & B & - & 153 \\
\hline
\end{tabular}

Table 4. Continued. SDPs of Chr 11 loci typed in SWXL RI strains. S and L represent alleles derived from SWR/J and C57L/J, respectively.

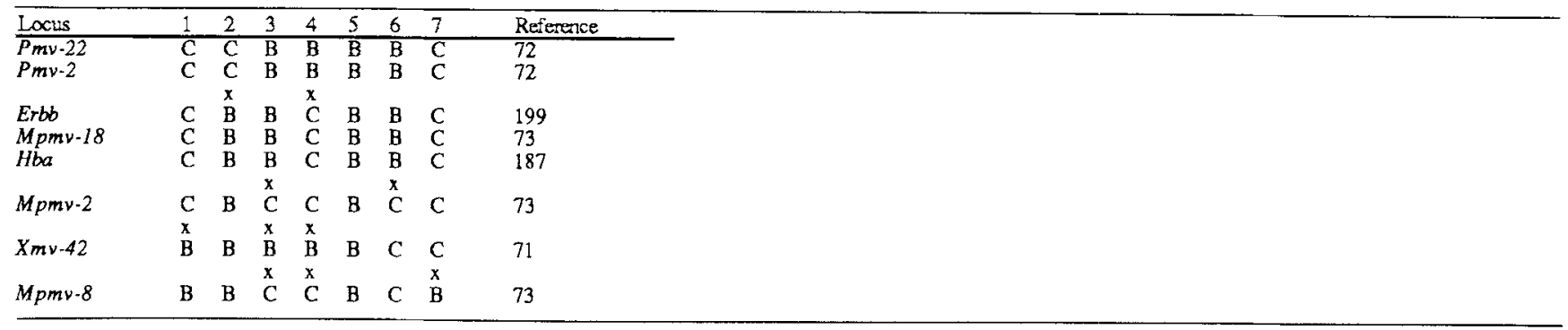

Table 4. Continued. SDPs of Chr 11 loci typed in AKXD RI strains. A and D represent alleles derived from AKR/J and DBA/2J, respectively.

\begin{tabular}{|c|c|c|c|c|c|c|c|c|c|c|c|c|c|c|c|c|c|c|c|c|c|c|c|c|c|c|c|c|}
\hline$\frac{\text { Locus }}{P_{m v-2}}$ & $\frac{1}{D}$ & $\frac{2}{A}$ & $\frac{3}{A}$ & $\frac{4}{-}$ & $\frac{5}{-}$ & $\frac{6}{A}$ & $\frac{7}{A}$ & $\begin{array}{l}8 \\
D\end{array}$ & $\frac{9}{A}$ & $\frac{10}{D}$ & $\frac{11}{D}$ & $\frac{12}{D}$ & $\frac{13}{D}$ & $\frac{14}{\mathrm{D}}$ & $\frac{15}{A}$ & $\frac{16}{A}$ & $\frac{17}{\mathrm{~A}}$ & $\frac{18}{\mathrm{~A}}$ & $\frac{20}{\mathrm{D}}$ & $\begin{array}{l}21 \\
\mathrm{D}\end{array}$ & $\frac{22}{\mathrm{D}}$ & $\frac{23}{\mathrm{D}}$ & $\frac{24}{\mathrm{~A}}$ & $\frac{25}{A}$ & $\frac{26}{D}$ & $\frac{27}{A}$ & $\frac{28}{\mathrm{D}}$ & $\frac{\text { Reference }}{72}$ \\
\hline Mpmv-18 & $\begin{array}{l}x \\
\mathrm{~A}\end{array}$ & A & $\begin{array}{l}\mathbf{x} \\
\mathrm{D}\end{array}$ & - & - & $\mathrm{A}$ & A & $\mathrm{x}$ & A & D & $x_{A}$ & $\begin{array}{l}x \\
A\end{array}$ & & $D$ & $x_{D}^{x}$ & & & & & & & & & & $x$ & & & \\
\hline & & & & & & & & & & D & A & A & $D$ & & $\begin{array}{l}D \\
x\end{array}$ & $\begin{array}{l}\mathrm{A} \\
\mathrm{x}\end{array}$ & - & A & $\mathrm{D}$ & D & $\begin{array}{l}\mathrm{D} \\
\mathbf{x}\end{array}$ & $\begin{array}{l}\mathrm{D} \\
\mathrm{x}\end{array}$ & $\begin{array}{l}A \\
x\end{array}$ & A & A & A & D & 73 \\
\hline$H b a$ & $\begin{array}{l}\mathrm{A} \\
\mathrm{x}\end{array}$ & D & D & A & D & A & A & A & A & D & A & A & D & $\begin{array}{l}D \\
x\end{array}$ & $\begin{array}{l}A \\
x\end{array}$ & D & A & A & $\mathrm{D}$ & D & A & A & D & $\begin{array}{l}A \\
\mathbf{x}\end{array}$ & A & A & D & 38 \\
\hline $\begin{array}{l}\text { Sparc } \\
\text { D4SIOh }\end{array}$ & $\begin{array}{l}D \\
D\end{array}$ & $\begin{array}{l}D \\
D\end{array}$ & $\begin{array}{l}\mathrm{D} \\
\mathrm{D}\end{array}$ & - & - & A & $\begin{array}{l}A \\
A\end{array}$ & A & $\stackrel{A}{A}$ & $\overline{\mathrm{D}}$ & $\overline{\mathrm{D}}$ & $\stackrel{A}{A}$ & $\begin{array}{l}\mathrm{D} \\
\mathrm{D}\end{array}$ & $\stackrel{A}{A}$ & $\begin{array}{l}\mathrm{D} \\
\mathrm{D}\end{array}$ & $\overline{\mathrm{D}}$ & $\overline{\mathrm{D}}$ & $\stackrel{\mathrm{A}}{\mathrm{A}}$ & $\begin{array}{l}\mathrm{D} \\
\mathrm{D}\end{array}$ & $\begin{array}{l}\mathrm{D} \\
\mathrm{D}\end{array}$ & $\overline{\mathrm{D}}$ & $\begin{array}{l}\text { A } \\
\text { A }\end{array}$ & $\overline{\mathrm{D}}$ & D & $\bar{A}$ & $\bar{A}$ & $\overrightarrow{\mathrm{D}}$ & $\begin{array}{l}139 \\
38\end{array}$ \\
\hline$E m v-14$ & $\mathrm{~A}$ & $\mathrm{~A}$ & D & - & - & $A$ & A & $\begin{array}{l}x \\
D\end{array}$ & A & D & D & A & $\begin{array}{l}\mathrm{x} \\
\mathrm{A}\end{array}$ & A & D & $\mathrm{D}$ & D & A & $\mathrm{D}$ & D & D & A & $\begin{array}{l}x \\
A\end{array}$ & D & A & A & D & 110 \\
\hline $\begin{array}{l}\text { Atpb }-2 \\
\text { Acrb } \\
\text { Glut4 }\end{array}$ & $\begin{array}{l}\bar{D} \\
D\end{array}$ & $\begin{array}{l}\mathrm{A} \\
\mathrm{A} \\
\mathrm{A}\end{array}$ & $\begin{array}{l}\mathrm{D} \\
\mathrm{D} \\
\mathrm{D}\end{array}$ & $\begin{array}{l}- \\
- \\
-\end{array}$ & $\begin{array}{l}- \\
- \\
-\end{array}$ & $\begin{array}{l}\text { A } \\
\text { A } \\
\text { A }\end{array}$ & $\begin{array}{l}\mathrm{A} \\
\mathrm{A} \\
\mathrm{A}\end{array}$ & $\begin{array}{l}\mathrm{D} \\
\mathrm{D} \\
\mathrm{D}\end{array}$ & $\begin{array}{l}\bar{A} \\
\mathrm{~A}\end{array}$ & $\begin{array}{l}\mathrm{D} \\
\mathrm{D} \\
\mathrm{D}\end{array}$ & $\begin{array}{l}\mathrm{D} \\
\mathrm{D} \\
\mathrm{D}\end{array}$ & $\begin{array}{l}\mathbf{A} \\
\mathrm{A} \\
\mathrm{A}\end{array}$ & $\begin{array}{l}\hat{D} \\
\mathrm{D} \\
\mathrm{D}\end{array}$ & $\begin{array}{l}\mathrm{A} \\
\mathrm{A} \\
\mathrm{A}\end{array}$ & $\begin{array}{l}D \\
D \\
D\end{array}$ & $\begin{array}{l}A \\
A \\
A\end{array}$ & $\begin{array}{l}- \\
-\end{array}$ & $\begin{array}{l}\text { A } \\
\text { A } \\
\text { A }\end{array}$ & $\begin{array}{l}\mathrm{D} \\
\mathrm{D} \\
\mathrm{D}\end{array}$ & $\begin{array}{l}D \\
D \\
D\end{array}$ & $\begin{array}{l}D \\
D \\
D\end{array}$ & $\begin{array}{l}\text { A } \\
\text { A } \\
\text { A }\end{array}$ & $\begin{array}{l}\mathrm{D} \\
\mathrm{D} \\
\mathrm{D}\end{array}$ & $\begin{array}{l}\mathrm{D} \\
\mathrm{D} \\
\mathrm{D}\end{array}$ & $\begin{array}{l}\text { D } \\
\text { D } \\
D\end{array}$ & $\begin{array}{l}\text { A } \\
\text { A } \\
\text { A }\end{array}$ & $\begin{array}{l}\mathrm{D} \\
\mathrm{D} \\
\mathrm{D}\end{array}$ & $\begin{array}{l}136 \\
90 \\
90\end{array}$ \\
\hline$E v i-2$ & $\mathrm{D}$ & A & D & A & $\mathrm{D}$ & A & $A$ & D & A & D & D & A & D & A & D & A & $\mathrm{D}$ & A & D & $\mathrm{D}$ & D & A & D & D & D & $\begin{array}{l}\mathrm{X} \\
\mathrm{D}\end{array}$ & D & 26 \\
\hline$X m v-20$ & - & - & - & - & - & $A$ & A & - & - & D & - & - & D & A & D & A & - & A & $\hat{A}$ & $\mathrm{D}$ & D & - & D & $\hat{A}$ & D & - & - & 71 \\
\hline $\begin{array}{l}\text { Cola-1 } \\
\text { Hox-2 }\end{array}$ & $\begin{array}{l}\mathrm{D} \\
\mathrm{D}\end{array}$ & $\stackrel{A}{A}$ & $\begin{array}{l}\mathrm{D} \\
\mathrm{D}\end{array}$ & - & - & $\begin{array}{l}\mathrm{A} \\
\mathrm{A}\end{array}$ & $\stackrel{A}{A}$ & $\begin{array}{l}\mathrm{D} \\
\mathrm{D}\end{array}$ & $\overline{\mathrm{A}}$ & $\overline{\mathrm{D}}$ & $\begin{array}{l}\mathrm{D} \\
\mathrm{D}\end{array}$ & $\begin{array}{l}\mathrm{D} \\
\mathrm{D}\end{array}$ & $\begin{array}{l}\mathrm{D} \\
\mathrm{D}\end{array}$ & $\begin{array}{l}\text { A } \\
\text { A }\end{array}$ & $\begin{array}{l}\mathrm{D} \\
\mathrm{D}\end{array}$ & $\begin{array}{l}\mathrm{A} \\
\mathrm{A}\end{array}$ & $\overline{\mathrm{D}}$ & $\begin{array}{l}\hat{D} \\
\mathrm{D}\end{array}$ & $\begin{array}{l}\mathrm{A} \\
\mathrm{A}\end{array}$ & $\begin{array}{l}\mathrm{D} \\
\mathrm{D}\end{array}$ & $\begin{array}{l}\mathrm{D} \\
\mathrm{D}\end{array}$ & $\stackrel{A}{A}$ & $\begin{array}{l}\mathrm{D} \\
\mathrm{D}\end{array}$ & $\stackrel{A}{A}$ & $\begin{array}{l}\mathrm{D} \\
\mathrm{D}\end{array}$ & $\begin{array}{l}\mathrm{D} \\
\mathrm{D}\end{array}$ & $\begin{array}{l}\mathrm{D} \\
\mathrm{D}\end{array}$ & $\begin{array}{l}4 \\
89\end{array}$ \\
\hline Cnp-1 & D & A & $\mathrm{D}$ & - & - & $A$ & $A$ & D & A & D & D & D & D & A & D & A & D & $\hat{A}$ & A & $\mathrm{D}$ & D & A & $\mathrm{D}$ & D & D & D & $\mathrm{D}$ & 18 \\
\hline Gfop & $\begin{array}{l}\mathrm{D} \\
\mathrm{x}\end{array}$ & $\begin{array}{l}A \\
x\end{array}$ & $\begin{array}{l}\mathrm{D} \\
\mathbf{x}\end{array}$ & - & - & $\begin{array}{l}A \\
x\end{array}$ & $\mathrm{D}$ & $\mathrm{D}$ & A & D & D & D & D & A & $\begin{array}{l}\mathrm{D} \\
\mathrm{x}\end{array}$ & A & A & A & A & D & $\mathrm{D}$ & A & $\hat{A}$ & D & $\mathrm{D}$ & $\mathrm{D}$ & $\mathrm{D}$ & 18 \\
\hline Gas & A & $\mathrm{D}$ & A & - & - & D & D & D & A & - & D & $\mathrm{D}$ & D & A & $A$ & A & - & A & A & D & $\mathrm{D}$ & A & A & - & $\mathrm{D}$ & D & D & 138 \\
\hline Mpmv-15 & A & D & A & - & - & A & $\mathrm{D}$ & D & A & D & D & D & D & A & A & A & - & A & $A$ & D & D & A & A & D & D & D & D & 73 \\
\hline
\end{tabular}


Table 4. Continued. SDPs of Chr 11 loci typed in SWXL RI strains. S and L represent alleles derived from SWR/J and C57L/S, respectively.

\begin{tabular}{lllllllll}
\hline Locus & 4 & 7 & 12 & 14 & 15 & 16 & 17 & Reference \\
\hline Sparc & S & L & L & L & - & S & S & 139 \\
Ahd-4 & S & - & L & L & S & S & - & 96 \\
Dlb-1 & S & L & S & S & S & S & S & 218 \\
\hline
\end{tabular}

Table 4. Continued. SDPs of Chr 11 loci typed in OXA RI strains. O and A represent alleles derived from O20/A and AKR/FuRdA, respectively.

\begin{tabular}{llllllllllllllll}
\hline Locus & 15 & 16 & 17 & 18 & 19 & 20 & 21 & 22 & 23 & 24 & 25 & 26 & 27 & 28 & Reference \\
\hline$l l-5$ & O & O & A & A & A & A & O & O & A & O & A & A & A & O & 226 \\
$l l-4$ & O & O & A & A & A & A & O & O & A & O & A & A & A & O & 210 \\
$l l .3$ & O & O & A & A & A & A & O & O & A & O & A & A & A & O & 210 \\
$T c a-3$ & X & A & x & & & & & & & & & & & x & \\
& A & A & O & A & A & A & O & O & A & O & A & A & A & A & 226 \\
\hline
\end{tabular}

Table 4. Continued. SDPs of Chr 11 loci typed in AXB RI strains. A and B represent alleles derived from $\mathrm{A} / \mathrm{J}$ and $\mathrm{C57BL} / 6 \mathrm{~J}$, respectively.

\begin{tabular}{|c|c|c|c|c|c|c|c|c|c|c|c|c|c|c|c|c|c|c|c|c|c|c|c|c|c|}
\hline $\begin{array}{l}\text { Locus } \\
P m v-2 \\
P m v-22 \\
\text { Erbb }\end{array}$ & $\begin{array}{l}1 \\
\mathrm{~A} \\
\mathrm{~A} \\
\mathrm{~A}\end{array}$ & $\begin{array}{l}2 \\
B \\
B \\
B\end{array}$ & $\begin{array}{l}\overline{3} \\
A \\
A \\
A\end{array}$ & $\begin{array}{l}4 \\
A \\
A \\
A\end{array}$ & $\begin{array}{l}5^{-} \\
A \\
\text { A } \\
-\end{array}$ & $\begin{array}{l}6 \\
A \\
A \\
A\end{array}$ & $\begin{array}{l}\text { i } \\
A \\
A \\
A\end{array}$ & $\begin{array}{l}8 \\
A \\
A \\
A\end{array}$ & $\begin{array}{l}\dot{9} \\
A \\
\text { A } \\
-\end{array}$ & $\begin{array}{l}10 \\
\text { A } \\
\text { A }\end{array}$ & $\begin{array}{l}11 \\
\mathrm{~A} \\
\mathrm{~A} \\
\mathrm{~A}\end{array}$ & $\frac{12}{\mathrm{~A}}$ & $\begin{array}{l}13 \\
A \\
-\end{array}$ & $\begin{array}{l}14 \\
\mathrm{~A} \\
\overline{\mathrm{A}}\end{array}$ & $\begin{array}{l}15 \\
\bar{B}\end{array}$ & $\begin{array}{l}17 \\
- \\
-\end{array}$ & $\begin{array}{l}18 \\
A \\
A \\
A\end{array}$ & $\begin{array}{l}19 \\
- \\
-\end{array}$ & $\begin{array}{l}20 \\
A \\
A \\
-\end{array}$ & $\begin{array}{l}21 \\
A \\
A \\
A\end{array}$ & $\begin{array}{l}\overline{22} \\
\mathrm{~B} \\
\mathrm{~B} \\
-\end{array}$ & $\begin{array}{l}23 \\
B \\
B \\
-\end{array}$ & $\begin{array}{l}24 \\
A \\
- \\
-\end{array}$ & $\begin{array}{l}25 \\
A \\
A \\
-\end{array}$ & $\begin{array}{l}\text { Refenenoe } \\
72 \\
72 \\
\text { Blatt (unpublished) }\end{array}$ \\
\hline$P_{m v-46}$ & A & B & A & A & A & $A$ & A & A & A & A & B & $\mathrm{A}$ & A & $\mathrm{B}$ & - & - & A & - & A & A & B & A & - & B & 72 \\
\hline$H b a$ & $\begin{array}{l}\mathrm{X} \\
\mathrm{B}\end{array}$ & B & $\mathbf{A}$ & A & A & A & A & A & A & $\begin{array}{l}\mathrm{X} \\
\mathrm{B}\end{array}$ & $\begin{array}{l}\mathbf{x} \\
\mathrm{A}\end{array}$ & A & $\begin{array}{l}\mathbf{x} \\
\mathbf{B}\end{array}$ & B & B & B & A & A & - & - & - & A & - & - & 130 \\
\hline ll-3 & B & B & A & $\hat{B}$ & A & A & $\mathrm{B}$ & A & $A$ & B & A & - & B & B & B & - & A & A & A & - & - & A & A & - & 130 \\
\hline Mpmv-2 & $\mathrm{B}$ & B & $\mathrm{A}$ & B & B & $\stackrel{\leftrightarrow}{B}$ & $\hat{A}$ & A & A & B & $\hat{\mathbf{B}}$ & $B$ & B & B & - & - & $\mathrm{A}$ & - & A & $B$ & B & A & $\mathrm{A}$ & A & 73 \\
\hline Myhs & B & B & A & B & A & A & - & A & - & B & $B$ & A & $\begin{array}{l}B \\
x\end{array}$ & B & A & $A$ & $\begin{array}{l}B \\
x\end{array}$ & A & A & $\mathrm{A}$ & B & A & A & - & 130 \\
\hline$X m v-42$ & B & B & A & B & A & A & A & A & B & B & $\hat{A}$ & A & A & B & - & - & A & - & A & B & A & A & A & B & 71 \\
\hline$M p m v-4$ & B & B & A & $\mathbf{A}$ & A & A & A & A & B & B & A & $\begin{array}{c}A \\
x\end{array}$ & A & B & - & - & $\begin{array}{l}A \\
x\end{array}$ & - & $\begin{array}{l}A \\
x\end{array}$ & B & A & A & A & B & 73 \\
\hline $\begin{array}{l}\text { Hox-2.1 } \\
\text { Hox } 2.6\end{array}$ & $\begin{array}{l}\text { B } \\
\text { B }\end{array}$ & $\begin{array}{l}\text { B } \\
\mathbf{B}\end{array}$ & $\begin{array}{l}\mathbf{A} \\
\mathbf{A}\end{array}$ & $\begin{array}{l}\hat{B} \\
\hat{B}\end{array}$ & $\begin{array}{l}A \\
A\end{array}$ & A & $\begin{array}{l}\mathrm{A} \\
\mathrm{A}\end{array}$ & $\begin{array}{l}A \\
A\end{array}$ & $\begin{array}{l}\mathrm{B} \\
\mathrm{B}\end{array}$ & $\begin{array}{l}\mathrm{B} \\
\mathrm{B}\end{array}$ & $\stackrel{A}{A}$ & $\begin{array}{l}\hat{B} \\
B\end{array}$ & $\stackrel{A}{A}$ & $\begin{array}{l}B \\
B\end{array}$ & $\begin{array}{l}\mathrm{B} \\
\mathrm{B}\end{array}$ & $\begin{array}{l}\mathrm{B} \\
\mathrm{B}\end{array}$ & $\begin{array}{l}\mathrm{B} \\
\mathrm{B}\end{array}$ & $\begin{array}{l}\mathrm{B} \\
\mathrm{B}\end{array}$ & $\begin{array}{l}\hat{\mathrm{B}} \\
\mathrm{B}\end{array}$ & $\begin{array}{l}\mathrm{B} \\
\mathrm{B}\end{array}$ & $\begin{array}{l}\text { A } \\
\text { A }\end{array}$ & $\stackrel{A}{A}$ & $\stackrel{A}{A}$ & - & $\begin{array}{l}130 \\
130\end{array}$ \\
\hline $\begin{array}{l}\text { Mpmv-8 } \\
P m v-56\end{array}$ & $\begin{array}{l}\text { B } \\
\text { B }\end{array}$ & $\begin{array}{l}\mathbf{B} \\
\mathbf{B}\end{array}$ & $\begin{array}{l}\hat{\mathbf{B}} \\
\mathbf{B}\end{array}$ & $\begin{array}{l}\text { B } \\
\text { B }\end{array}$ & $\stackrel{A}{A}$ & $\begin{array}{l}A \\
A\end{array}$ & $\hat{A}$ & $\begin{array}{l}\mathrm{B} \\
\mathrm{B}\end{array}$ & $\begin{array}{l}\mathrm{B} \\
\mathrm{B}\end{array}$ & $\begin{array}{l}\mathrm{B} \\
\mathrm{B}\end{array}$ & $\stackrel{A}{A}$ & $\begin{array}{l}\mathrm{B} \\
\mathrm{B}\end{array}$ & $\begin{array}{l}A \\
A\end{array}$ & $\begin{array}{l}\text { B } \\
\text { B }\end{array}$ & - & - & $\begin{array}{l}\mathrm{B} \\
\mathrm{B}\end{array}$ & - & $\begin{array}{l}\text { B } \\
\text { B }\end{array}$ & $\begin{array}{l}\text { B } \\
\text { B }\end{array}$ & $\begin{array}{l}\ddot{B} \\
\text { B }\end{array}$ & $\stackrel{A}{A}$ & $\begin{array}{l}A \\
A\end{array}$ & $\begin{array}{l}\text { B } \\
B\end{array}$ & $\begin{array}{l}73 \\
72\end{array}$ \\
\hline$E s-3$ & B & B & $\hat{A}$ & $\stackrel{x}{A}$ & A & $\begin{array}{l}x \\
B\end{array}$ & A & $\hat{\mathbf{B}}$ & $\mathbf{A}$ & B & A & $\AA$ & $\mathbf{A}$ & B & B & B & B & B & B & B & - & A & A & - & 130 \\
\hline
\end{tabular}

Table 4. Continued. SDPs of Chr 11 loci typed in BXA RI strains. B and A represent alleles derived from C57BL/6J and A/J, respectively.

\begin{tabular}{|c|c|c|c|c|c|c|c|c|c|c|c|c|c|c|c|c|c|c|c|c|c|c|c|c|c|}
\hline Locus & 1 & 2 & 3 & 4 & 5 & 6 & 7 & 8 & 9 & 10 & 11 & 12 & 13 & 14 & 16 & 17 & 18 & 19 & 20 & 21 & 22 & 23 & 24 & 25 & Reference \\
\hline$P_{m v-2}$ & A & B & - & $\mathrm{A}$ & - & $\mathrm{B}$ & A & B & A & $\mathrm{A}$ & $\overline{\mathrm{B}}$ & B & $\mathrm{B}$ & A & - & B & $\mathrm{A}$ & A & $\mathrm{A}$ & - & $\mathrm{A}$ & $A$ & $\mathrm{~A}$ & $\bar{A}$ & 72 \\
\hline$P m v-22$ & A & B & - & A & - & B & $\mathbf{A}$ & B & $\mathbf{A}$ & A & B & B & B & A & - & $\mathrm{A}$ & $\mathrm{A}$ & $\mathrm{B}$ & A & - & $\mathrm{A}$ & A & $A$ & A & 72 \\
\hline $\begin{array}{l}\text { Erbb } \\
P m v-46\end{array}$ & $\overline{\mathrm{A}}$ & $\overline{\mathrm{B}}$ & $\begin{array}{l}\text { B } \\
-\end{array}$ & $\begin{array}{l}\mathbf{A} \\
\mathbf{A}\end{array}$ & $\begin{array}{l}\text { A } \\
-\end{array}$ & $\overline{\mathrm{A}}$ & $\mathbf{A}$ & $\hat{A}$ & $\overline{\mathrm{A}}$ & $\overline{\mathrm{A}}$ & $\underset{\mathrm{B}}{\mathrm{B}}$ & $\overline{\mathrm{A}}$ & $\overline{\mathrm{A}}$ & $\vec{A}$ & - & $\bar{A}$ & $\overline{\mathrm{A}}$ & $\overline{\mathrm{A}}$ & $\overline{\mathrm{A}}$ & $\bar{A}$ & $\overline{\mathrm{A}}$ & $\tilde{\mathrm{A}}$ & $\overline{\mathrm{A}}$ & $\overline{\mathrm{A}}$ & $\begin{array}{l}\text { Blatt (unpublished) } \\
72\end{array}$ \\
\hline$H b a$ & A & - & - & A & - & - & - & A & - & - & B & A & A & A & A & $\mathrm{A}$ & $\mathrm{A}$ & A & $\hat{\mathbf{B}}$ & - & - & - & A & - & 130 \\
\hline$n-3$ & A & B & B & B & - & $\mathbf{A}$ & $\mathbf{A}$ & - & $\mathrm{B}$ & - & B & - & A & A & - & - & $A$ & $\mathrm{X}$ & - & - & $A$ & - & $\mathrm{A}$ & - & 130 \\
\hline$M p m v-2$ & A & B & - & B & - & $\begin{array}{l}\mathbf{x} \\
\mathbf{B}\end{array}$ & $\mathbf{A}$ & B & B & A & $\begin{array}{l}\mathbf{x} \\
\mathbf{A}\end{array}$ & $\mathrm{A}$ & $\stackrel{\mathrm{x}}{\mathrm{B}}$ & A & - & B & A & - & B & - & $A$ & A & A & B & 73 \\
\hline Myhs & A & B & - & B & - & B & $\mathrm{A}$ & B & B & $\mathrm{A}$ & $\mathbf{B}$ & B & B & A & A & B & A & B & - & - & $A$ & - & $\mathrm{A}$ & - & 130 \\
\hline$X m v-42$ & $\begin{array}{l}\mathrm{x} \\
\mathrm{B}\end{array}$ & B & - & $B$ & - & B & A & $\begin{array}{l}\mathbf{x} \\
\mathbf{A}\end{array}$ & B & A & $\begin{array}{l}\mathbf{x} \\
\mathrm{A}\end{array}$ & B & B & $\begin{array}{l}\mathrm{x} \\
\mathrm{B}\end{array}$ & - & $\begin{array}{l}x \\
\mathrm{~A}\end{array}$ & $\mathrm{~A}$ & B & A & - & A & B & $\mathrm{A}$ & B & 71 \\
\hline Mpmy-4 & B & B & - & B & - & B & $A$ & A & B & $A$ & A & B & B & B & - & A & A & - & A & - & A & B & $A$ & $\grave{A}$ & 73 \\
\hline $\begin{array}{l}H o x-2.1 \\
H o x-2.6\end{array}$ & $\begin{array}{l}\mathrm{B} \\
\mathrm{B}\end{array}$ & $\underset{B}{B}$ & A & $\begin{array}{l}\mathrm{B} \\
\mathrm{B}\end{array}$ & - & $\begin{array}{l}\text { B } \\
\text { B }\end{array}$ & $\begin{array}{l}\mathbf{A} \\
\mathbf{A}\end{array}$ & $\begin{array}{l}\mathrm{A} \\
\mathrm{A}\end{array}$ & $\begin{array}{l}\mathbf{B} \\
\mathbf{B}\end{array}$ & $\begin{array}{l}\text { A } \\
\text { A }\end{array}$ & $\overline{\mathrm{A}}$ & $\begin{array}{l}\text { B } \\
\text { B }\end{array}$ & $\begin{array}{l}\mathrm{B} \\
\mathrm{B}\end{array}$ & $\begin{array}{l}\mathrm{B} \\
\mathrm{B}\end{array}$ & $\begin{array}{l}\mathrm{A} \\
\mathrm{A}\end{array}$ & $\bar{A}$ & $\mathrm{~A}$ & A & $\mathrm{A}$ & - & $\overline{\mathrm{A}}$ & - & $\begin{array}{l}\hat{\mathbf{B}} \\
\mathbf{B}\end{array}$ & $\begin{array}{l}- \\
-\end{array}$ & $\begin{array}{l}130 \\
130\end{array}$ \\
\hline Hox -2.3 & B & B & B & B & - & B & $\mathrm{A}$ & $\mathrm{A}$ & B & - & $A$ & B & B & B & A & $\mathrm{A}$ & A & A & A & - & A & - & $B$ & - & 130 \\
\hline Mpmv-8 & B & B & - & B & - & $\hat{\mathbf{A}}$ & A & A & B & A & $\mathrm{A}$ & B & B & B & - & $\mathrm{A}$ & A & A & A & - & $A$ & A & B & $\mathrm{A}$ & 73 \\
\hline$P m v-56$ & B & B & - & B & - & $A$ & $\mathbf{A}$ & A & B & A & A & B & B & B & - & $\hat{\mathbf{B}}$ & A & A & A & - & $\mathrm{A}$ & A & B & A & 72 \\
\hline$E s-3$ & B & $\hat{A}$ & B & B & - & $\begin{array}{l}\mathrm{x} \\
\mathrm{B}\end{array}$ & $\mathbf{A}$ & A & B & - & A & - & B & $\stackrel{\mathbf{x}}{\mathrm{A}}$ & A & $\begin{array}{l}\mathrm{x} \\
\mathrm{A}\end{array}$ & $\mathrm{A}$ & A & A & - & $\begin{array}{l}\mathrm{x} \\
\mathrm{B}\end{array}$ & - & B & - & 130 \\
\hline
\end{tabular}


Tabie 4. Contimued. SDPs of Chr 11 loci lyped in CXS RI strains. C and S represeni alleles derived from BALB/cHeA and STS/A, respectively.

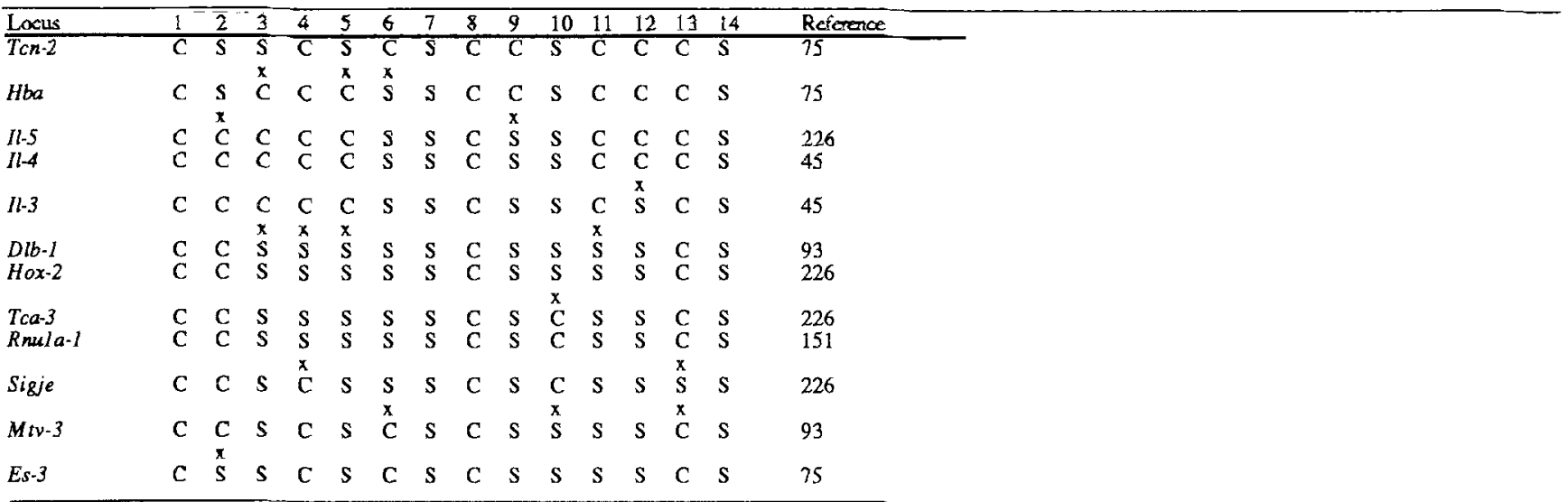

Table 4. Continued. SDPs of Chr 11 loci typed in NXSM RI strains. N and S represent alleles derived from NZB/B1NRe and SM/J, respectively.

\begin{tabular}{|c|c|c|c|c|c|c|c|c|c|c|c|c|c|c|c|c|c|c|}
\hline$\frac{\text { Locus }}{T \text { Tcn-2 }}$ & $\begin{array}{l}\mathrm{A} \\
\mathrm{S}\end{array}$ & $\begin{array}{l}\mathrm{C} \\
\mathrm{S}\end{array}$ & $\frac{D}{N}$ & $\frac{E}{S}$ & $\begin{array}{l}\mathrm{F} \\
\mathrm{S}\end{array}$ & I & $\frac{L}{N}$ & $\frac{\mathrm{N}}{\mathrm{N}}$ & $\begin{array}{l}\mathrm{P} \\
\mathrm{S}\end{array}$ & $\frac{Q}{N}$ & $\frac{T 1}{S}$ & $\frac{T 2}{S}$ & $\begin{array}{l}\mathrm{U} \\
\mathrm{S}\end{array}$ & $\frac{\mathrm{V}}{\mathrm{N}}$ & & $\begin{array}{l}\mathrm{X} \\
\mathrm{S}\end{array}$ & $\frac{2}{N}$ & $\begin{array}{l}\text { Reference } \\
62\end{array}$ \\
\hline Erbb & $\begin{array}{l}x \\
S\end{array}$ & $S$ & $\begin{array}{l}x \\
S\end{array}$ & $S$ & $S$ & $s$ & $N$ & $\mathbf{N}$ & $\mathbf{S}$ & $S$ & $S$ & $s$ & $\mathrm{~s}$ & $\begin{array}{l}x \\
S\end{array}$ & $S$ & $S$ & $\mathrm{~N}$ & 62 \\
\hline$H b a$ & $\begin{array}{l}\mathrm{x} \\
\mathrm{N}\end{array}$ & $\begin{array}{l}\mathbf{x} \\
\mathrm{N}\end{array}$ & $\begin{array}{l}\mathbf{x} \\
\mathbf{N}\end{array}$ & $\begin{array}{l}x \\
N\end{array}$ & $S$ & $S$ & $\mathrm{~N}$ & $\mathrm{~N}$ & $\mathbf{S}$ & $S$ & $S$ & 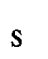 & $S$ & $\stackrel{x}{N}$ & $S$ & $S$ & $\mathbf{N}$ & 62 \\
\hline Evi-2 & $\stackrel{x}{S}$ & $\mathbf{N}$ & $\mathbf{N}$ & $\begin{array}{l}x \\
s\end{array}$ & $\begin{array}{l}x \\
N\end{array}$ & $S$ & $\mathbf{N}$ & $\mathrm{N}$ & $\begin{array}{l}\mathrm{x} \\
\mathrm{N}\end{array}$ & $S$ & & $\mathrm{x}$ & $S$ & $\mathrm{x}$ & $S$ & & $N$ & 62 \\
\hline$G h$ & $s$ & $\mathrm{~N}$ & $\mathrm{~N}$ & $S$ & $\mathbf{N}$ & $s$ & $\mathrm{~N}$ & $\mathbf{N}$ & $\mathbf{N}$ & $\begin{array}{l}\mathbf{x} \\
\mathbf{N}\end{array}$ & $\begin{array}{l}x \\
S\end{array}$ & $\begin{array}{l}x \\
S\end{array}$ & $\mathrm{~S}$ & $\begin{array}{l}\mathbf{x} \\
\mathbf{N}\end{array}$ & $S$ & $\mathrm{~N}$ & $\mathbf{N}$ & 62 \\
\hline$M t v-3$ & $s$ & $\mathrm{~N}$ & $\mathbf{N}$ & $s$ & $\mathbf{N}$ & $s$ & $\mathrm{~N}$ & $\mathrm{~N}$ & $\mathbf{N}$ & $\begin{array}{l}\mathbf{x} \\
\mathbf{S}\end{array}$ & $S$ & $\mathbf{S}$ & $S$ & $\mathbf{N}$ & $S$ & $\mathrm{~N}$ & $\mathbf{N}$ & 62 \\
\hline
\end{tabular}

Table 5. Cytogenetic localization of genes on mouse Chr 11.

\begin{tabular}{lll}
\hline Gene name & Band location & Reference \\
\hline Cola-1 (Mov-13) & D & 160 \\
DIIWas70 & Chr 11 & 58 \\
Erbb & A1-A4 & 159 \\
Hox-2 & D & 158 \\
Il-3 & AS-B1 & 221 \\
Il-5 & A5-B) & 221 \\
Lif & A1-A2 & 119 \\
Mov-9 & BS & 160 \\
Mpo & C-E & 184 \\
Myhs-f & B2-C & 159 \\
Nos & A1-A5 & 144 \\
Rasa & D & 142 \\
Rnu3b & C-D & 146 \\
Rnu3b-1 & C-D & 146 \\
Rnu3b-2 & C-D & 146 \\
Rnu3b-3 & C-D & 146 \\
Rnu3b-4 & C-D & 146 \\
Rpo2-1 & B1-C & 180 \\
Sparc & B1 & 139 \\
Tk-1 & B3-E2 & 98 \\
Trp53 & B2-C & 159 \\
\hline
\end{tabular}

Table 6. List of variant chromosomes involving mouse Chr 11. NA means not applicable.

\begin{tabular}{|c|c|c|}
\hline Variant name & Breakpoint & Reference \\
\hline \multicolumn{3}{|c|}{ Robertsonian fusions } \\
\hline $\mathrm{Rb}(1.1 \mathrm{l}) 2 \mathrm{Mpl}$ & NA & 188 \\
\hline $\mathrm{Rb}(4.11) 12 \mathrm{Rma}$ & $\mathrm{NA}$ & 35 \\
\hline $\mathbf{R b}(9.11) 14 \mathrm{Tu}$ & $\mathrm{NA}$ & $3,23,24$ \\
\hline $\mathrm{Rb}(10.11) 8 \mathrm{Bnr}$ & NA & 86,35 \\
\hline $\mathrm{Rb}(10.11) 5 \mathrm{Rma}$ & NA & $34,35,82$ \\
\hline $\mathrm{Rb}(11.13) \mathrm{ABnr}$ & NA & $233,84,85,83$ \\
\hline $\mathrm{Rb}(11.13) 6 \mathrm{Lub}$ & $\mathrm{NA}$ & $82,227,228$ \\
\hline $\mathbf{R b}(11,13) 6 \mathrm{Tu}$ & $\mathrm{NA}$ & 3 \\
\hline $\mathrm{Rb}(11.14) \mathrm{dn}$ & $\mathbf{N A}$ & 50 \\
\hline $\mathrm{Rb}(11.16) 2 \mathrm{H}$ & NA & 134 \\
\hline \multicolumn{3}{|l|}{ Translocations } \\
\hline$T(X: 11) 384$ & XAl, IIEI & $194,65,193,15$ \\
\hline$T\{21\}) 4 \mathrm{Dn}$ & 20,1135 & 49 \\
\hline$T(2 ; 1) 30 \mathrm{H}$ & ZHI, I IB & $36,15,3 ?$ \\
\hline$T(3 ; 11) 16 \mathrm{Ad}$ & $3 F 1,11 B 5$ & 49 \\
\hline$T(5 ; 11) 17$ Ad & 5B,11B1 & 49 \\
\hline$\tau(9 ; 11) 9$ Ad & $9 B 1,11 \mathrm{D}$ & 2 \\
\hline$T(11 ; 16) 530 \pi$ & $11 D, 16 A$ & 49 \\
\hline$T(11 ; 17) 390 n$ & $11 \mathrm{D}, 17 \mathrm{~A} 2$ & 49 \\
\hline$T(11 ; 19) 424$ & $11 \mathrm{D}, 19 \mathrm{~B}$ & $194,64,16,118$ \\
\hline \multicolumn{3}{|c|}{ Chromosomal inversions } \\
\hline $\operatorname{In}(11) 20 \mathrm{n}$ & $11 \mathrm{~A} 4,11 \mathrm{~B} 1$ & 48 \\
\hline In(11) 201Rk & $11 \mathrm{~A} 2,11 \mathrm{D}$ & 52,51 \\
\hline
\end{tabular}


Table 7. Mouse Chr 11 loci defined by microsatellite sequences. Locus name is listed in the first column, DNA sequence of the primet pairs is given in the second and third columns in $5^{\prime}-3^{\prime}$ orientation. Columns 4,5 , and 6 provide information about the polymorphism detected for the microsatellites in intraspecific (I) backcrosses, intersubspecific (C) backcrosses involving Mus castaneus, and interspecific backcrosses (S) with $M$. spretus, respectively. (Y) indicates that a polymorphism was detected in only one out of six strains tested, $\mathrm{N}$ indicates no polymorphism was detected, and - indicates the primer pair was not tested.

\begin{tabular}{|c|c|c|c|c|c|c|}
\hline \multirow[b]{2}{*}{ Loais } & \multirow[b]{2}{*}{ Primer 1} & \multirow[b]{2}{*}{ Primer 2} & \multicolumn{3}{|c|}{ Polymorphic } & \multirow[b]{2}{*}{ Reference } \\
\hline & & & & & & \\
\hline Ace & ATAACACCAACATTACCATAGAGGG & ATACTAAGTTCAGACTTTTCACCAATTTT & - & $\begin{array}{l}\mathbf{Y} \\
\end{array}$ & - & 57 \\
\hline Acrb & AGGCTACACAAAGAAACTTTGACTTGA & GCTCAGGAATCCCTGGAACTCCA & $\mathbf{Y}$ & - & $\mathrm{Y}$ & 90 \\
\hline AntP9Ja & CATGTGCGCGCGATGAGACTT & TGACITGGCCTATCACCATGT & $\mathbf{Y}$ & - & $\mathbf{Y}$ & 90 \\
\hline$A n t P 9 J a$ & CCACTTAGTATATCTTGTCC & GCATGACTTGGCCTATCACC & $\mathbf{Y}$ & $\mathbf{Y}$ & $\mathbf{Y}$ & 57 \\
\hline$A n t P 9 J a$ & AGCCAGGGCTTGGTAGAGAGA & ATGTTTTCTCTCCTGTCTAGCG & $\mathrm{Y}$ & - & $\mathbf{Y}$ & 90 \\
\hline Atplb2 & AGCATGGATTAACATATCTGG & ATTGAGGTCAGGAGTTCAAGG & $\mathrm{Y}$ & - & $\mathbf{Y}$ & 90 \\
\hline Cola-I & ATGGATAGGGACTTGTGTGAA & CTTCTTAAATAGCACCTTCAG & (Y) & - & $\mathbf{Y}$ & 4 \\
\hline Csfgm & CTGTGCAACAGACTAAGCCT & CTGTAACACAATAACCAGGCA & $\mathbf{Y}$ & $\mathbf{Y}$ & $\mathbf{Y}$ & $32 \mathrm{a}, 131,90$ \\
\hline Csfgm & TATTTTCTACTGATAGGGACC & TTATTCTGGTAAGACATTCTC & $\mathbf{N}$ & - & $\mathbf{N}$ & \\
\hline DIJMiII & GGGTCTCTGAAGGCTITGTG & TGAATACAGAAGCCACGGTG & $(\mathrm{Y})$ & $\mathbf{Y}$ & $\mathbf{Y}$ & 57 \\
\hline DIIMit2 & TCCCAGAGGTCTCCAAGACA & CCACAGTGTGTGATGTCTTC & $(\mathrm{M})$ & $\mathbf{Y}$ & $\mathbf{Y}$ & 57 \\
\hline DIIMit4 & CAGTGGGTCATCAGTACAGCA & AAGCCAGCCCAGTCTTCATA & $\mathrm{Y}$ & $\mathrm{Y}$ & $\mathbf{Y}$ & 57 \\
\hline DIIMitS & TTCTGTGAGCCTGGAGGAGT & TACAGGACTAGTTTCCATTTGGG & $Y$ & $\mathbf{Y}$ & - & 57 \\
\hline DIIMit7 & AGGGTATTCTCTAGCCTCCACAC & TTTGAGGCAAGATGTCATGTATG & $\mathbf{N}$ & $\mathbf{Y}$ & $\mathbf{Y}$ & 57 \\
\hline DIIMit8 & CTTTTCATGGAGGCACAGGT & TGTGAACAGAGACACACATTCA & $(\mathrm{Y})$ & $\mathbf{Y}$ & - & 57 \\
\hline DIIMit10 & GAACCGCAAGTCATGAATCA & TGGTTTATTCCTGAAGCTGC & $(\mathrm{Y})$ & $\mathbf{Y}$ & $\mathrm{Y}$ & 57 \\
\hline DIIMit11 & TATTCTCTCCTTCCCCCCAC & TAGAGTTGGGACACCCAAGC & $(\mathrm{Y})$ & $\mathbf{Y}$ & $\mathbf{Y}$ & 57 \\
\hline DIIMit12 & AGGGTTATGCTCTTGGCTGC & GATTTTCCTAGGCTGGCTGG & Y & $\mathbf{Y}$ & $(\mathrm{Y})$ & 57 \\
\hline DIINdsI & TAAGAACCTTCTGTAGTTATT & ACCITAGTTAGAGTTGGTCTC & $(N)$ & $\mathrm{Y}$ & $\mathbf{Y}$ & 57 \\
\hline D1INds2 & TTATGTATGAATGTCCAC & AGGTTCGATTCCCAACAC & $(\mathrm{Y})$ & - & $\mathbf{Y}$ & 90 \\
\hline $\begin{array}{l}\text { Empl-3 } \\
\text { Enpb-3 }\end{array}$ & $\begin{array}{l}\text { GCTCAGACTCCTAGGTACTTAC } \\
\text { TCCTTATTCTGTTGATTGGCAG }\end{array}$ & $\begin{array}{l}\text { ACTCTGTGTCTACTAGGTCTAG } \\
\text { CTATAGAGAAATCCTGTCTTG }\end{array}$ & $\begin{array}{l}\mathbf{N} \\
\mathbf{Y}\end{array}$ & $\begin{array}{l}- \\
-\end{array}$ & $\begin{array}{l}\mathrm{Y} \\
\mathrm{Y}\end{array}$ & $\begin{array}{l}90 \\
131,90\end{array}$ \\
\hline $\begin{array}{l}\text { Gap } \\
\text { Gfap } \\
\text { Gfap } \\
\text { Gfap } \\
\text { Gfap }\end{array}$ & $\begin{array}{l}\text { AACTGTTCAAAGCCATTTCG } \\
\text { TGAATTCTAGGACCAGCCAAGGCT } \\
\text { CAGCTCTGCCCTTCTGAGTG } \\
\text { CCTAGGTCCTGGCTCTGTGTA } \\
\text { GTACTAAAACGTCTACAAGTGG }\end{array}$ & $\begin{array}{l}\text { CTATGGACTCACAGCCAGGCT } \\
\text { ACCTCTAAGATCCTGTGCGAGGCT } \\
\text { TTGGCCTTCTTGGTGCTTTCC } \\
\text { CAGAGTATCTCCTTGGAGCTC } \\
\text { GCGGATATATATGCAGCAGAG }\end{array}$ & $\begin{array}{l}(\mathrm{Y}) \\
(\mathrm{Y}) \\
(\mathrm{Y}) \\
(\mathrm{Y})\end{array}$ & $\begin{array}{l}- \\
- \\
- \\
- \\
-\end{array}$ & $\begin{array}{l}Y \\
Y \\
Y \\
(Y) \\
Y\end{array}$ & $\begin{array}{l}131 \\
131 \\
131 \\
90 \\
90\end{array}$ \\
\hline Glns & AGCTTTGGAGACAACAATTAGATC & TGTTCATCAGCTGAGGAATGGATG & $\mathbf{Y}$ & $\mathrm{Y}$ & $\mathbf{Y}$ & $32 \mathrm{a}, 131,90$ \\
\hline Glut-4 & $\begin{array}{l}\text { GCGGAGCTAACGTGGGAACTA } \\
\text { TGACATTTGGCGGAGCTAAC }\end{array}$ & $\begin{array}{l}\text { AAGAATTGAGTGCAGCTGGTC } \\
\text { ACATGTACTTGCCAGGGTAC }\end{array}$ & $\begin{array}{l}\mathbf{Y} \\
\mathbf{Y}\end{array}$ & $\overline{\mathrm{Y}}$ & $\begin{array}{l}\mathbf{Y} \\
\mathbf{Y}\end{array}$ & $\begin{array}{l}90 \\
57\end{array}$ \\
\hline$H o x-2$ & CCTTGCATTCTGAGGCTGAAGGAC & TCAGAAGTCTTGCGCTGCATC & $\mathbf{Y}$ & - & $\mathbf{Y}$ & 131,90 \\
\hline$n-3$ & GAAATCTCAAATAGCAGGCACACT & TCTCCGAAAGCTCTTATTCTAAGA & $\mathbf{N}$ & $\mathbf{Y}$ & $\mathbf{Y}$ & $32 \mathrm{a}, 90$ \\
\hline$I l-4$ & GTCTGCTGTGGCATATTCTG & GGCATTTCTCATTCAGATTC & $(\mathrm{Y})$ & $\mathbf{Y}$ & $\mathbf{Y}$ & $32 \mathrm{a}, 131$ \\
\hline $\begin{array}{l}l l-5 \\
l l-5 \\
l l-5 \\
l-5 \\
l l-5\end{array}$ & $\begin{array}{l}\text { CCTTTCTGAAAGTATTAAGAGT } \\
\text { GGCTACACAGAGAAACCCTGT } \\
\text { AGCTTCTCATGTTCCGCAGTGGCACT } \\
\text { TGATTGATATGCTTACTTATG } \\
\text { CTTTAAATAGTGCAATTATGGC }\end{array}$ & $\begin{array}{l}\text { ACAACCATCTGCATATCCAGC } \\
\text { CATGCATACACAGGTAGTTCA } \\
\text { CATGTTTAAAAAAAAAACATACTAAGGAGC } \\
\text { GAAGTCAGCTACAGTGTATTC } \\
\text { AATAGAGCTTATTCAGGGCAT }\end{array}$ & $\begin{array}{l}(Y) \\
(M) \\
\stackrel{N}{N} \\
N\end{array}$ & $\begin{array}{l}Y \\
- \\
- \\
-\end{array}$ & $\begin{array}{l}\mathbf{Y} \\
\mathbf{Y} \\
\mathbf{Y} \\
\mathbf{N} \\
\mathbf{Y}\end{array}$ & $\begin{array}{l}32 \mathrm{a}, 131 \\
90 \\
90 \\
90 \\
90\end{array}$ \\
\hline Lif & CAGCTAGAAATGGCAATGAGG & CTTGTTCTACACCCAGCAAGC & $\mathbf{Y}$ & $\mathbf{Y}$ & $\mathrm{Y}$ & 57 \\
\hline Mpo & GTGAGTTCTAGGACAGCCAGG & ACAACCACTTCTTCACCCATGG & $(\mathrm{Y})$ & - & $(\mathbf{Y})$ & 90 \\
\hline Myla & ACTAGTCCTACCGGTCTTCCA & TGTCTGTTGCTTACTATGTGC & $\mathbf{Y}$ & - & $\mathbf{Y}$ & 131,90 \\
\hline Rpo2-1 & TGTCTGAAGACAGCTACAGTGTAC & AGTGGCCAGGACACTCGGTCATGT & $\mathbf{N}$ & - & $\mathbf{N}$ & 90 \\
\hline Sigje & GGATCAGAGATACTCATGAT & GAGAAGATTACCTGAGTACA & $\mathbf{N}$ & - & $\mathbf{Y}$ & 4 \\
\hline
\end{tabular}




\section{Microsatellite markers}

Polymorphisms detectable by the polymerase chain reaction (PCR) have several advantages over restriction fragment length polymorphisms (RFLPs) detected by Southern blot analyses in that less DNA is consumed, samples can be typed rapidly, and probes can be readily exchanged by publishing oligonucleotide primer sequences. In addition, microsatellites such as mono- and dinucleotide repeat sequences tend to exhibit more polymorphisms among closely related strains than do restriction fragments. Table 7 presents a summary of the oligonucleotide primer sequences that have been used to identify loci on $\mathrm{Chr} 11$. For some loci there are several primer pairs available; not all of these have been tested in a wide variety of strains, but it is evident that some are more informative than others.

\section{Reference mapping loci}

To aid in incorporating new mapping information into the existing consensus map, a set of reference loci were suggested for use (Buchberg et al. 1991). The characteristics of these reference loci include: spacing every 5-15 cM, ease of use, universal availability, and useful polymorphisms. The original set of reference loci proposed by the Chr 11 mapping committee has been expanded as follows, with the estimated distance (cM) between neighboring markers:

$$
\begin{gathered}
\text { Lif-5-Erbb-10-Glns-5-Adra-1-9-CSfgm- } \\
\text { 10-Acrb-7-DIIMit8-5-Mpo-6- } \\
\overline{\text { Hox }-2-6-\text { Myla }-14-\underline{\text { P4hb}} .}
\end{gathered}
$$

The underlined loci are primary anchors and have been confirmed in independent crosses (Buchberg et al. 1991). The newly proposed reference loci have not been mapped relative to one another in multilocus crosses; therefore, they are listed as secondary anchors. Nonetheless, this set of 12 loci spans $76 \mathrm{cM}$ of the $80 \mathrm{cM}$ of $\mathrm{Chr} 11$, providing complete coverage of Chr 11. The community is encouraged to incorporate the use of these loci as markers in their genetic mapping experiments.

DNA probes corresponding to these genes have been requested to be deposited in ATCC. Polymorphisms can be detected by PCR for nine of the anchors: Lif, Glns, Csfgm, Acrb, DI1Mit8, Mpo, Hox-2, and Gfap (Table 7). Ideally, it will be possible to type each reference locus with a probe that is informative in both intraspecific as well as interspecific backcrosses by both conventional Southern blotting and PCR analysis.

\section{Conclusions}

Part of the objective of this report is to provide a mechanism for routine review of the mapping data that have been published and to generate a consensus map that corrects errors and omissions in previous reports. We apologize for any references or data that may have been excluded in this report. We welcome the receipt of additional information and suggestions concerning the consensus linkage map. We appreciate authors' sending us reprints of new papers that report the mapping of genes to mouse Chr 11 .

Acknowledgments. The various online genetic databases GBASE, OMIM, and GDB were extremely useful in the preparation of this report. We would like to thank N. Copeland, W. Dietrich, M. Davisson, D. Doolittle, J.-L. Guénet, N. Jenkins, C. Kozak, E. Lander, D. Morris, J. Nadeau, T. Robinson, and B. Taylor for the sharing of unpublished data used in this report. We thank L. Siracusa for critical review of this manuscript.

\section{References}

1. Abbot, C., Piaggio, G., Ammendola, R., Solomon, E., Povey, S., Gounari, F., De Simone, V., and Cortese, R.: Mapping of the gene TCF2 for the transcription factor LFB3 to human chromosome 17 by polymerase chain reaction. Genomics 8 : $165-167,1990$.

2. Adler, I.D. and Neuhäuser-Klaus: Seventeen stocks of mice with reciprocal or Robertsonian translocations. Mouse News Lett 77: 139-142, 1987.

3. Adolf, S. and Klein, J.: Robertsonian variation in Mus musculus from Central Europe, Spain and Scotland. J Hered 72 : 219-221, 1981.

4. Aitman, T.J., Hearne, C.M., McAleer, M.A., and Todd, J.A.: Mononucleotide repeats are in abundant source of length variants in mouse genomic DNA. Mammalian Genome 1: 206-210, 1991.

5. Archer, B.T.I., Ozcelik, T., Jahn, R., Francke, U., and Sudhof, T.C.: Structures and chromosomal localizations of two human genes encoding synaptobrevins 1 and 2. J Biol Chem 265: 17267-17273, 1990.

6. Arwert, F., Porck, H.J., Frater-Schroder, M., Brahe, C., Geurts van Kessel, A., Westerveld, A., Meera Khan, P., Zang, K., Frants, R.R., Kortbeek, H.T., and Eriksson, A.W.: Assignment of human transcobalamin II (TC2) to chromosome 22 using somatic cell hybrids and monosomic meningioma cells. Hum Genet 74: 378-381, 1986.

7. Ashworth, A., Williams, B.P., Buchberg, A.M., Goodfellow, P.N., Solomon, E., Potter, J., and Willison, K.R.: Chromosomal localization of zinc finger protein genes in man and mouse. Genomics 4: 323-327, 1989.

8. Bailey, D.W. and Bunker, H.P.: Located histocompatibility genes. Mouse News Lett 47: 18, 1972.

9. Baldacci, P.A., Richoux, V., Renard, J.-P., Guénet, J.-L., and Babinet, C.: The locus Om, responsible for the DDK syndrome, maps close to Sigje on mouse Chromosome 11. Mammalian Genome 2: 100-105, 1992.

10. Barker, D., Wright, E., Nguyen, K., Cannon, L., Fain, P., Goldgar, D., Bishop, D.T., Carey, J., Baty, B., Kivlin, J., Willard, H., Waye, J.S., Greig, G., Leinwand, L., Nakamura, Y., O'Connell, P., Leppert, M., Lalouel, J.-M., White, R., and Skolnick, M.: Gene for von Recklinghausen neurofibromatosis is in the pericentromeric region of chromosome 17. Science 236: 1100-1102, 1987.

11. Barletta, C., Batticane, N., Ragusa, R.M., Leube, R.E., Peschle, C., and Romano, V.: Subchromosomal localization of two human cytokeratin genes (KRT4 and KRT15) by in situ hybridization. Cytogenet Cell Genet 54: 148-150, 1990.

12. Barlow, D.P., Bucan, M., Lehrach, H., Hogan, B.L.M., and Gough, N.M.: Close genetic and physical linkage between the murine haemopoietic growth factor genes GM-CSF and MULTI-CSF (IL3), EMBO J 6: 617-623, 1987.

13. Bartke, A.: Histology of the anterior hypophysis, thyroid and gonads of two types of dwarf mice. Anat Rec 149: 225-235, 1964.

14. Bartolomei, M.S. and Corden, J.L.: Localization of an alphaamanitin resistance mutation in the gene encoding the largest 
subunit of mouse RNA polymerase II. Mol Cell Biol 7: 586$594,1987$.

15. Beechey, C.V. and Searle, A.G.: Mouse News Lett 59: 19-20, 1978.

16. Beechey, C.V. and Searle, A.G.: Mouse News Lett 70: 81 , 1984.

17. Beeson, D., Jeremiah, S., West, L.F., Povey, S., and Newsom-Davis, J.: Assignment of the human nicotinic acetylcholine receptor genes: the alpha and delta subunit genes to chromosome 2 and the beta subunit gene to chromosome 17. Ann Hum Genet 54: 199-208, 1990.

18. Bernier, L., Colman, D.R., and D'Eustachio, P.: Chromosomal locations of genes encoding $2^{\prime}, 3^{\prime} \mathrm{cyclic}$ nucleotide $3^{\prime}$ phosphodiesterase and glial fibrillary acidic protein in the mouse. J Neurosci Res 20: 496-504, 1988.

19. Berube, D., Seralini, G.E., Gagne, R., and Hammond, G.L.: Localization of the human sex hormone-binding globulin gene (SHBG) to the short arm of chromosome 17 (17p12-p13). Cytogenet Cell Genet 54: 65-67, 1990.

20. Biddle, F.: Es-3-oe-co linkage. Mouse News Lett 46:20, 1972.

21. Blatt, C., Mileham, K., Haas, M., Nesbitt, M.N., Harper, M.E., and Simon, M.I.: Chromosomal mapping of the mink cell focus-inducing and xenotropic env gene family in the mouse. Proc Natl Acad Sci USA 80: 6298-6302, 1983.

22. Bongcam-Rudloff, E., Nister, M., Betsholtz, C., Wang, J.-L., Stenman, G., Huebner, K., Croce, C.M., and Westermark, B.: Human glial fibrillary acidic protein: complementary DNA cloning, chromosome localization and messenger RNA expression in human glioma cell lines. Cancer Res 51: 1991.

23. Brooker, P.C.: Robertsonian translocations in Mus musculus from NE. Scotland and Orkney. Heredity 48: 305-309, 1982.

24. Brooker, P.C. and Berry, R.J.: Mouse News Lett 64: 65-66, 1981.

25. Brownell, E., Kozak, C.A., Fowle, J.R., III, Modi, W.S., Rice, N.R., and O'Brien, S.J.: Comparative genetic mapping of cellular rel sequences in man, mouse, and the domestic cat. Am J Hum Genet 39: 194-202, 1986.

26. Buchberg, A.M., Bedigian, H.G., Taylor, B.A., Brownell, E., Ihle, J.N., Nagata, S., Jenkins, N.A., and Copeland, N.G.: Localization of Evi-2 to Chromosome 11: linkage to other proto-oncogenes and growth factor loci using interspecific backcross mice. Oncogene Res 2: 149-165, 1988.

27. Buchberg, A.M., Brownell, E., Nagata, S., Jenkins, N.A., and Copeland, N.G.: A comprehensive genetic map of murine Chromosome 11 reveals extensive linkage conservation between mouse and human. Genetics 122: 153-161, 1989.

28. Buchberg, A.M., Gilbert, D.J., Cho, B., Jenkins, N.A., and Copeland, N.G. The linkage map of the distal half of mouse chromosome 11 reveals extensive synteny with human chromosome 17. In Fourth International Workshop for Mouse Genome Mapping, Annapolis, Md., 1990.

29. Buchberg, A.M., Moskow, J.J., Buckwalter, M.S., and Camper, S.A.: Mouse Chromosome 11. Mammalian Genome 1 (Suppl): S158-S191, 1991.

30. Buckle, V.J., Fujita, N., Bateson, A.N., Darlison, M.G., and Barnard, E.A.: Localization of human GABA-A receptor subunit genes to chromosomes 4 and 5. Cytogenet Cell Genet 5I: 972, 1989.

31. Buckle, V.J., Higgs, D.R., Wilkie, A.O., and Weatherall, D.J.: Localisation of human alpha globin to 16 p13.3-pter. $J$ Med Genet 25: 847-849, 1988.

32. Buckwalter, M.S., Katz, R.W, and Camper, S.A.: Localization of the panhypopituitary dwarf mutation $(\mathrm{df})$ on mouse chromosome 11 in an intersubspecific backcross. Genomics 10. 515-526, 1991.

32a. Camper, S.A.: Unpublished results.

33. Cannizzaro, L.A., Emanuel, B.S., Cho, K.W.Y., and Weinmann, R.: The gene encoding the large subunit of human RNA polymerase II is located on the short arm of chromosome 17. Am J Hum Genet 38: 812-818, 1986.

34. Capanna, E., Cristaldi, M., Perticone, P., and Rizone, M.: Identification of chromosomes involved in the 9 Robertsonian fusions of the Apennine mouse with a 22-chromosome karyotype. Experientia 31: 294-296, 1975.

35. Capanna, E., Gropp, A., Winking, H., Noack, G., and Civi- telli, M.V.: Robertsonian metacentrics in the mouse. Chromosoma 58: 341-353, 1976.

36. Cattanach, B.M.: Chemically induced mutations in mice. $\mathrm{Mu}$ tat. Res. 3: 346-353, 1966.

37. Cattanach, B.M. and Kirk, M.: Differential activity of maternally and paternally derived chromosome regions in mice. $\mathrm{Na}$ ture 315: 496-498, 1985.

38. Cheng, S.V., Lugo, T.G., Tanzi, R.E., Whitney, J.B.I., Fornier, R.E.K., and Gusella, J.F.: Chromosomal localization of the mouse homolog of the Huntington's disease linked G8 (D4S10) marker. DNA 6: 401-407, 1987.

39. Cho, M., Villani, V., and D'Eustachio, P.: A linkage map of distal mouse Chromosome 12. Mammalian Genome 1: 30-36, 1991.

40. Colombo, M.P., Martinotti, A., Howard, T.A., Schneider, C., D'Eustachio, P., and Seldin, M.F.: Localization of growth arrest-specific genes on mouse Chromosomes $1,7,8,11,13$ and 16. Mammalian Genome 2: 130-134, 1992.

41. Cornall, R.J., Aitman, T.J., Hearne, C.M., and Todd, J.A.: The generation of a library of PCR-analyzed microsatellite variants for mapping of the mouse genome. Genomics 10:874 $881,1991$.

42. Cox, R.D., Copeland, N.G., Jenkins, N.A., and Lehrach, H.: Interspersed repetitive element polymerase chain reaction product mapping using a mouse interspecific backcross. Genomics 10: 375-384, 1991.

43. Czosnek, H., Nudel, U., Shani, M., Barker, P.E., Pravtcheva, D.D., Ruddle, F.H., and Yaffe, D.: The genes coding for the muscle contractile proteins, myosin heavy chain, myosin light chain 2, and skeletal muscle actin are located on three different mouse chromosomes. EMBO J 1: 1299-1305, 1982.

44, Czosnek, H.H., Bienz, B., Givol, D., Zakut-Houri, R., Pravtcheva, D.D., Ruddle, F.H., and Oren, M.: The gene and the pseudogene for mouse p53 cellular tumor antigen are located on different chromosomes. Mol Cell Biol 4: 1638-1640, 1984.

45. D'Eustachio, P., Brown, M., Watson, M., and Paul, W.E.: The Il-4 gene maps to Chromosome 11, near the gene encoding IL-3. J Immunol 141: 3067-3071, 1988.

46. Danciger, M., Tuteja, N., Kozak, C.A., and Farber, D.B.: The gene for the gamma-subunit of retinal cGMP-phosphodiesterase is on mouse Chromosome 11. Exp Eye Res 48: 303$308,1989$.

47. Davies, A.A., Moss, S.E., Crompton, M.R. Jones, T.A., Spurr, N.K.S., D., Kozak, C., and Crumpton, M.J.: The gene coding for the p68 calcium-binding protein is localised to bands q32-q34 of human chromosome 5, and to mouse chromosome 11. Hum Genet 82: 234-238, 1989.

48. Davisson, M.T.: New chromosome aberrations. Mouse News Lett 80: 166, 1988

49. Davisson, M.T.: New chromosome aberrations. Mouse Genome 89: $288,1991$.

50. Davisson, M.T. and Akeson, E.C.: Mouse News Lett 69: 26, 1983.

51. Davisson, M.T., Hawes, N., and Roderick, T.H.: Mouse News Lett 57: 19-20, 1977.

52. Davisson, M.T. and Roderick, T.H.: Localization of cytological breakpoints in induced chromosome rearrangements in the mouse (Mus musculus). Manuscript in preparation, 1988.

53. Debuire, B., Henry, C., Benaissa, G., Claverie, J.M., Saule, S., Martin, P., and Stehelin, D.: Sequencing the erbA gene of avian erythroblastosis virus reveals a new type of oncogene. Science 224: 1456-1459, 1984.

54. Dickie, M.M.: Alopecia, a dominant mutation in the house mouse. $J$ Hered 46: 31-34, 1955.

55. Dickie, M.M.: Lustrous (lt). Mouse News Lett 40: 29, 1969.

56. Dickie, M.M. and Deol, M.S.: Mouse News Lett 36: 39, 1967.

57. Dietrich, W., Katz, H., Lincoln, S.E., Shin, H.-S., Friedman, J., Dracopoli, N., and Lander, E.S.: A genetic map of the mouse suitable for typing intraspecific crosses. Genetics, in press, 1992.

58. Disteche, C.M., Tantravahi, U., Gandy, S., Eisenhard, M., Adler, D., and Kunkel, L.M.: Isolation and characterization of two repetitive DNA fragments located near the centromere of 
the mouse X Chromosome. Cytogenet Cell Genet 39: 262-268, 1985.

59. Do, M.S. and Lonai, P.: Gene organization of murine homeobox-containing gene clusters. Genomics 3: 195-200, 1988.

60. Dobrovolskaia-Zavadskaia, N.: L'irradiation des testicules et l'hérédité chez la souris. Arch Biol 38: 457-501, 1928.

61. Edwards, Y.H., Parkar, M., Povey, S., West, L.F., Parrington, J.M., and Solomon, E.: Human myosin heavy chain genes assigned to chromosome 17 using a human cDNA clone as probe. Ann Hum Genet 49: 101-109, 1985.

62. Eicher, E.M. and Lee, B.K.: The NXSM recombinant inbred strains of mice: genetic profile for 58 loci including the MtV proviral loci. Genetics 125: 431-446, 1990.

63. Elliott, R.W., Lee, B.K., and Eicher, E.M.: Localization of the growth hormone gene to the distal half of mouse Chromosome 11. Genomics 8: 591-594, 1990.

64. Evans, E.P., Beechey, C.V., and Searle, A.G.: Mouse News Lett 57: 17, 1977.

65. Evans, E.P., Burtenshaw, M.D., and Lyon, M.F.: A repositioning of the $X$ chromosome breakpoint of $\mathrm{T}(\mathrm{X} ; 11) 38 \mathrm{H}$. Mouse News Lett 77: 147, 1987.

66. Falconer, D.S.: Linkage of rex with shaker-2 in the house mouse. Heredity 1: 133-135, 1947.

67. Falconer, D.S.: Two new mutants, "trembler" and "reeler," with neurological action in the house mouse (Mus musculus). $J$ Genet 50: 192-201, 1951.

68. Ferguson, J.M. and Wallace, M.E.: Mouse News Lett 57: 11, 1977.

69. Flanagan, S.P.: 'Nude' a new hairless gene with pleiotropic effects in the mouse. Genet Res 8: 294-309, 1966.

70. Frankel, W.N., Coffin, J.M., Cote, M., Seyfried, T.N., Rise, M., Rajan, T.V., Nelson, F.K., Selsing, E., and Gerstein, R.: Backcross data for endogenous Mpmv, Pmv, and Xmv proviruses. Mouse Genome 89: 266-270, 1991.

71. Frankel, W.N., Stoye, J.P., Taylor, B.A., and Coffin, J.M.: Genetic analysis of endogenous xenotropic murine leukemia viruses: association with two common mouse mutations and viral restriction locus Fv-1. J Virol 63: 1763-1774, 1989.

72. Frankel, W.N., Stoye, J.P., Taylor, B.A., and Coffin, J.M.: Genetic identification of endogenous polytropic proviruses by using recombinant inbred mice. $J$ Virol $63: 3810-3821,1989$.

73. Frankel, W.N., Stoye, J.P., Taylor, B.A., and Coffin, J.M.: A linkage map of endogenous murine leukemia proviruses. $G e-$ netics 124: 221-236, 1990.

74. Frater-Schroder, M., Haller, O., Gmur, R., Kierat, L., and Anastasi, S.: Allelic forms of mouse transcobalamin 2. Biochem Genet 20: 1001-1014, 1982.

75. Frater-Schroder, M., Prochazka, M., Haller, O., Arwert, F., Porck, H.J., Skow, L.C., Lundin, L.G., Hilkens, J., and Hilgers, J.: Localization of the gene for the vitamin B 12 binding protein transcobalamin II, near the centromere on mouse Chromosome 11, linked with the hemoglobin alpha-chain locus. Biochem Genet 23: 139-153, 1985 .

76. George, A.L.J., Ledbetter, D.H., Kallen, R.G., and Barchi, R.: Assignment of a human skeletal muscle sodium channel alpha-subunit gene (SCN4A) to 17q23.1-25.3. Genomics 9: 555-556, 1991.

77. Goldman, D. and Pikus, H.J.: Fourteen genetically variant proteins of mouse brain: discovery of two new variants and chromosomal mapping of four loci. Biochem Genet 24: 183194, 1986

78. Gough, N.M., Gough, J., Metcalf, D., Kelso, A., Grail, D., Nicola, N.A., Burgess, A.W., and Dunn, A.R.: Molecular cloning of cDNA encoding a murine haematopoietic growth regulator, granulocyte-macrophage colony stimulating factor. Nature 309: 763-767, 1984.

79. Graham, A., Papalopulu, N., and Krumlauf, R.: The murine and Drosophila homeobox gene complexes have common features of organization and expression. Cell 57: 367-378, 1989.

80. Green, E.L.: Shambling, a neurological mutant of the mouse. $J$ Hered 58: 65-68, 1967.

81. Green, M.C., Catalog of mutant genes and polymorphic loci. In M.F. Lyon and A.G. Searle (eds.); Genetic Variants and Strains of the Laboratory Mouse, pp. 12-403, Oxford University Press, Oxford, 1989.
82. Gropp, A.: Mouse News Lett 57: 27-28, 1977.

83. Gropp, A., Kolbus, U., and Giers, D.: Systematic approach to the study of trisomy in the mouse. II. Cytogenet Cell Genet 14: $42-62,1975$.

84. Gropp, A., Tettenborn, U., and von Lehmann, E.: Chromosomenuntersuchungen bei der Tabakmaus ( $M$. poschiavinus) und bei Tabakmaus-Hybriden. Experientia 25: 875-876, 1969.

85. Gropp, A., Tettenborn, U., and von Lehmann, E.: Chromosomenvariationen vom Robertson'schen Typus bei der Tabakmaus, $M$. poschiavinus, und ihren Hybriden mit der Laboratoriumsmaus. Cytogenetics 9: 9-23, 1970.

86. Gropp, A., Winking, H., Zech, L., and Müller, H.: Robertsonian chromosomal variation and identification of metacentric chromosomes in feral mice. Chromosoma 39: 265-288, 1972.

87. Guénet, J,-L.: Personal communication. In Fifth International Workshop on Mouse Genome Mapping, Lunteren, The Netherlands, 1991.

88. Gusella, J.F., Gibbons, K., Hobbs, W., Heft, R., Anderson, M., Rashtchian, R., Folstein, S., Wallace, P., and Conneally, P.M.a.T., R.: The G8 locus linked to Huntington's disease (abstract). Am J Hum Genet 36: 139S, 1984.

89. Hart, C.P., Dalton, D.K., Nichols, L., Hunihan, L., Roderick, T.H., Langley, S.H., Taylor, B.A., and Ruddle, F.H.: The Hox-2 homeobox gene complex on mouse Chromosome 11 is closely linked to Re. Genetics 118: 319-327, 1988.

90. Hearne, C.M., McAleer, M.A., Love, J.M., Aitman, T.J., Cornall, R.J., Ghosh, S., Knight, A.M., Prins, J.-B., and Todd, J.A.: Additional microsatellite markers for mouse genome mapping. Mammalian Genome 1: 273-282, 1991.

91. Heidmann, O, Buonanno, A., Geoffroy, B., Robert, B., Guénet, J.-L., Merlie, J.P., and Changeaux, J.P.: Chromosomal localization of muscle nicotinic acetylcholine receptor genes in the mouse. Science 234: 866-868, 1986.

92. Heston, W.E.: The "vestigial tail" mouse. J Hered 42: 71-74, 1951.

93. Hilgers, J. and Poort-Keesom, R.: Strain distribution pattern of genetic polymorphisms between BALB/cHeA and STS/A strains. Mouse News Lett 76: 14-26, 1986.

94. Hogan, A., Heyner, S., Charron, M.J., Copeland, N.G., Gilbert, D.J., Jenkins, N.A., Thorens, B., and Schultz, G.A.: Glucose transporter gene expression in early mouse embryos. Development, in press, 1991.

95. Hoggan, M.D., O'Neill, R.R., and Kozak, C.A.: Nonecotropic murine leukemia viruses in $B A L B / c$ and NFS/N mice: characterization of the $\mathrm{BALB} / \mathrm{c} \mathrm{Bxv}-1$ provirus and the single NFS endogenous xenotrope. J Virol 60: 980-986, 1986.

96. Holmes, R.S., Popp, R.A., and VandeBerg, J.L.: Genetics of ocular $\mathrm{NAD}<+>$-dependent alcohol dehydrogenase in the mouse: evidence for genetic identity with stomach isozymes and localization of Ahd- 4 on Chromosome 11 near trembler. Biochem Genet 26: 191-205, 1988.

97. Holmes, R.S. and Rout, U.K.: Distribution of $A h d-4$ variants among mouse strains. Mouse News Lett 81: 53, 1988.

98. Hozier, J., Applegate, M., de Vassal, N., and Sawyer, J.: Localization of the cytoplasmic thymidine kinase gene $(T k-1)$ on mouse Chromosome 11 by in situ molecular hybridization and comparison of human and mouse mapping sites at high cytogenetic resolution. Cytogenet Cell Genet 46: 631, 1987.

99. Hsieh, C., Birnbaum, M.J., and Francke, U. Assignment of glucose transporter genes to mouse chromosomes 4 (Glut-1) and 11 (Glut-4). In Fourth International Workshop for Mouse Genome Mapping, Annapolis, Md., 1990.

100. Hsieh, C.L., Cheng-Deutsch, A., Gloor, S., Schachner, M. and Francke, U.: Assignment of Amog (adhesion molecule on glia) gene to mouse Chromosome 11 near Zfp-3 and Asgr-1,2 and to human Chromosome 17. Somatic Cell Mol Genet 16: $401-405,1990$.

101. Huebner, K., Isobe, M., Chao, M., Bothwell, M., Ross, A.H., Finan, J., Hoxie, J.A., Sehgal, A., Buck, C.R., Lanahan, A., Nowell, P.C., Koprowski, H., and Croce, C.M.: The nerve growth factor receptor gene is at human chromosome region $17 \mathrm{q} 12-17 \mathrm{q} 22$, distal to the chromosome 17 breakpoint in acute leukemias. Proc Nat Acad Sci 83: 1403-1407, 1986.

102. Huebner, K., Nagarajan, L., Besa, E., Angert, E., Lange, B.J., Cannizzaro, L.A., van den Berghe, H., Santoli, D., Fi- 
nan, J., Croce, C.M., and Nowell, P.C.: Order of genes on human chromosome $5 q$ with respect to $5 q$ interstitial deletions. Am J Hum Genet 46: 26-36, 1990.

103. Hull, E., Sarkar, M., Spruijt, M.P.N., Hoppener, I.W.M., Dunn, R., and Schacter, H.: Organization and localization to chromosome 5 of the human UDP- $N$-acetylglucosamine:alpha3-D-mannoside beta-1,2- $N$-acetylglucosaminyltransferase 1 gene. Biochem, Biophys Res Commun 176: 608-615, 1991.

104. Ihle, J.N., Silver, J., and Kozak, C.A.: Genetic mapping of the mouse interleukin 3 gene to Chromosome 11. I Immunol 138: 3051-3054, 1987.

105. Irving, S.G., Zipfel, P.F., Balke, J., McBride, O.W., Morton, C.C., Burd, P.R., Siebenlist, U., and Kelly, K.: Two inflammatory mediator cytokine genes are closely linked and variably amplified on chromosome 17q. Nucleic Acids Res 18: 32613270, 1990.

106. Itoh, S., Harada, H., Nakumra, Y., White, R., and Taniguchi, T.: Assignment of the human interferon regulatory factor-1 (IRF-I) gene to chromosome 5q23-q31. Genomics 10: 1097$1099,1991$.

107. Jackson, 1.: An anonymous cDNA clone maps to the distal tip of Chromosome 11. Mouse Genome 86: 226, 1990.

108. Jackson-Grusby, L.L., Pravtcheva, D., Ruddle, F.H., and Linzer, D.I.H.: Chromosomal mapping of the prolactin/growth hormone family in the mouse. Endocrinology 122: 2462-2466, 1988.

109. Jaenisch, R., Jahner, D., Nobis, P., Simon, I., Lohler, J., Harbers, K., and Grotkopp, D.: Chromosomal position and activation of retroviral genomes inserted into the germ line of mice. Cell 24: 519-529, 1981.

110. Jenkins, N.A., Copeland, N.G., Taylor, B.A., and Lee, B.K.: Dilute $(d)$ coat colour mutation in DBA/2J mice is associated with the site of integration of an ecotropic MuLV genome. Nature 293: 370-374, 1981.

111. Jenkins, N.A., Copeland, N.G., Taylor, B.A., and Lee, B.K.: Organization, distribution, and stability of endogenous ecotropic murine leukemia virus DNA sequences in chromosomes of Mus musculus. J Virol 43: 26-36, 1982.

112. Joseph, D.R., Adamson, M.C., and Kozak, C.A.: Genetic mapping of the gene for androgen-binding protein/sex hormone-binding globulin to mouse chromosome 11. Cytogenet Cell Genet 56: 122-124, 1991.

113. Joyner, A.L., Lebo, R.V., Kan, Y.W., Tjian, R., Cox, D.R., and Martin, G.R.: Comparative chromosome mapping of a conserved homoeo box region in mouse and human. Nature 314: 173-175, 1985.

113a. Karolyi, I.J., Guénet, J.-L., Rey-Campos, J., and Camper, S.A.: The gene coding for variant hepatic nuclear factor-1 (Tcf2) maps between the $E d p-I$ and Erba genes on mouse chromosome 11. Mammaitan Genome 3; 184-185, 1992.

114. Kaupmann, K., Simon-Chazottes, D., Cuénet, J.-L., and Jockusch, H.: Wobbler, a mutation affecting motoneuron survival and gonadal functions in the mouse, maps to proximal chromosome 11. Genomics, in press, 1991.

115. Keeler, C.E.: A second rexoid coat character in the house mouse. J Hered 26: 189-191, 1935.

116. Keir, W.J., Kozak, C.A., Chakraborti, A., Deitrich, R.A., and Sikela, J.M.: The cDNA sequence and chromosomal location of the murine GABA>A<alpha1 receptor gene.-Genomics 9: 390-395, 1991.

117. Killary, A.M. and Fournier, R.E.K.: A genetic analysis of extinction: trans-dominant loci regulate expression of liverspecific traits in hepatoma hybrid cells. Cell 38: 523-534, 1984.

118. Kirk, K.M. and Searle, A.G.: Phenotypic consequences of chromosome imbalance in the mouse. In I. A. Daniel (ed.); The Cytogenetics of Mammalian Autosomal Rearrangements, pp. 739-768, Alan Liss, New York, 1988.

119. Kola, I., Davey, A., and Gough, N.M.: Localization of the murine leukemia inhibitory factor gene near the centromere on Chromosome 11. Growth Factors 2: 235-240, 1990.

120. Kozak, C, Danciger, M., and Farber, D.: Chromosome assignment in the mouse of the genes for several proteins involved in visual transduction (abstract). Cytogenet Cell Genet 51: $1025,1989$.

121. Kozak, C.A. Personal communication. In Fifth International
Workshop on Mouse Genome Mapping, Lunteren, The Netherlands, 1991.

122. Kozak, C.A. and Rowe, W.P.: Genetic mapping of ecotropic murine leukemia virus-inducing loci in six inbred strains. J Exp Med 155: 524-534, 1982.

123. Kozak, C.A. and Ruddle, F.H.: Assignment of the genes for thymidine kinase and galactokinase to Mus musculus Chromosome 11 and the preferential segregation of this chromosome in Chinese hamster mouse somatic cell hybrids. Somatic Cell Genet 3: 121-133, 1977.

124. Lane, P.W.: Vibrator, vb. Mouse News Lett 50: 44, 1974.

125. Lane, P.W., Ganser, A.L., Kerner, A.L., and White, W.F.: Spasmodic, a mutation on Chromosome 11 in the mouse. $J$ Hered 78: 353-356, 1987.

126. Ledbetter, D.H., Ledbetter, S.A., vanTuinen, P., Summers, K.M., Robinson, T.J., Nakamura, Y., Wolff, R., White R., Barker, D.F., Wallace, M.R., Collins, F.S., and Dobyns, W.B.: Molecular dissection of a contiguous gene syndrome: frequent submicroscopic deletions, evolutionarily conserved sequences, and a hypomethylated "island" in the MillerDieker chromosome region. Proc Natl Acad Sci USA, 1989.

127. Lee, J.S. and Young, I.G.: Fine-structure mapping of the murine IL-3 and GM-CSF genes by pulsed-field gel electrophoresis and molecular cloning. Genomics 5: 359-362, 1989.

128. Leinwand, L.A., Fournier, R.E.K., Nadel-Ginard, B., and Shows, T.B.: Multigene family for sarcomeric myosin heavy chain in mouse and human DNA: localization on a single chromosome. Science 221: 766-768, 1983.

129. Levine, M., Rubin, G.M., and Tjian, R.: Human DNA sequences homologous to a protein coding region conserved between homeotic genes of Drosophila. Cell 38: 667-673, 1984.

130. Lonai, P., Arman, E., Czosnek, H., Ruddle, F.R., and Blatt, C.: New murine homeoboxes: structure, chromosomal assignment, and differential expression in adult erythropoiesis. DNA 6: $409-418,1987$.

131. Love, J.M., Knight, A.M., McAleer, M.A., and Todd, J.A.: Toward construction of a high resolution map of the mouse genome using PCR-analyzed microsatellites. Nucleic Acids Res 18: 4123-4130, 1990.

132. Lyon, M.F. and Glenister, P.H.: Bareskin (Bsk). Mouse News Lett 71: 26, 1984.

133. Lyon, M.F. and Glenister, P.H.: Chylous ascites (Chy) on Chromosome 11. Mouse News Lett 72: 106-107, 1985.

134. Lyon, M.F., Mason, I.M., and Bigger, T.R.L.: Mouse News Lett 56: 37, 1977.

135. Mackensen, J.S.: "Open eyelids" in newborn mice. J Hered 5I: 188-190, 1960.

136. Malo, D., Schurr, E., Levenson, R, and Gros, P.: Assignment of $\mathrm{Na}, \mathrm{K}$-ATPase beta>2<-subunit gene (Atpb-2) to mouse Chromosome 11. Genomics 6: 697-699, 1990.

137. Martiniuk, F., Ellenbogen, A., Hirschhorn, K., and Hirschhorn, R.: Further regional localization of the genes for human acid alpha glucosidase (GAA), peptidase D (PEPD) and alpha mannosidase B $(M A N B)$ by somatic cell hybridization. Hum Genet 69: 109-111, 1985.

138. Martinjuk, F., Hirschorn, R., and D'Eustachio, P.: Linkage of acid $\alpha$-glucosidase and thymidine kinase $(T k-1)$ to esterase-3 $(E s-3)$ on mouse chromosome 11. Mammalian Genome 1:267269, 1991

139. Mason, I.J., Murphy, D., Munke, M., Francke, U., Elliott, R.W., and Hogan, B.L.M.: Developmental and transformation-sensitive expression of the Sparc gene on mouse Chromosome 11. EMBO J 5: 1831-1837, 1986.

140. Mather, P.B. and Holmes, R.S.: Biochemical genetics of aldehyde dehydrogenase isozymes in the mouse: evidence for stomach- and testis-specific isozymes. Biochem Genet 22: 981$995,1985$.

141. Mattei, M.-G., Hubert, C., Alhenc-Gelas, F., Roeckel, N., Corvol, P., and Soubrier, F.: Angiotensin-I converting enzyme is on chromosome 17. Cytogenet Cell Genet 51: 1041, 1989.

142. Mattei, M.-G., Riviere, M., Krust, A., Ingvarsson, S., Vennstrom, B., Islam, M.Q., Levan, G., Kautner, P., Zelent, A., Chambon, P., Szpirer, J., and Szpirer, C.: Chromosomal assignment of retinoic acid receptor (RAR) genes in the human, mouse, and rat genomes. Genomics 10: 1061-1069, 1991. 
143. Mattei, M.G., Dautigny, A., Pham-Dinh, D., Passage, E., Mattei, J.F., and Jolles, P.: The gene encoding the large human neurofilament subunit $(\mathrm{NF}-\mathrm{H})$ maps to the q12. 1 -q13.1 region on human chromosome 22. Hum Genet 80:293-295, 1988.

144. Mattei, M.G., Passage, E., Mattei, J.F., Dautigny, A., PhamDinh, D., and Jolles, P.: Localization of the gene coding for the large mouse neurofilament subunit $N f h$. Mouse News Lett 84: 96, 1989.

145. Mazan, S. and Bachellerie, J.P.: Structure and organization of mouse U3B RNA functional genes. J Biol Chem 263: 1946119467, 1988.

146. Mazan, S., Mattei, M.G., Passage, E., and Bachellerie, J.P.: Composition and chromosomal localization of the small multigene family encoding mouse U3B nucleolar RNA. Cytogenet Cell Genet 56: 18-22, 1991.

147. McBride, O.W., Merry, D., and Givol, D.: The gene for human p53 cellular tumor antigen is located on chromosome 17 short arm (17p13). Proc Natl Acad Sci 83: 130-134, 1986.

148. Mehrabian, M., Sparkes, R.S., Mohandas, T., Fogelman, A.M., and Lusis, A.J.: Localization of monocyte chemotactic protein-1 gene (SCYA2) to human chromosome 17q11.2-q21.1. Genomics 9: 200-203, 1991.

149. Meier, H.: The neuropathy of teetering, a neurological mutation in the mouse. Arch Neurol 16: 59-66, 1967.

150. Meruelo, D., Rossomando, A., Scandalis, S., D'Eustachio, P., Fournier, R.E.K., Roop, D.R., Saxe, D., Blatt, C., and Nesbitt, M.N.: Assignment of the Ly-6-Ril-1-Sis-H-30-Pol5/ $X m m v-72-I n s-3-K r t-1-I n t-1-G d c-1$ region to murine chromosome 15. Immunogenetics 25: 361-372, 1987.

151. Michael, S.K., Hilgers, J., Kozak, C., Whitney, J.B.I., and Howard, E.F.: Characterization and mapping of DNA sequence homologous to mouse Ulal snRNA: localization on Chromosome 11 near the Dlb-1 and Re loci. Somatic Cell Mol Genet 12: 215-223, 1986.

152. Miller, M.D., Wilson, S.D., Dorf, M.E., Seuanez, H.N., O'Brien, S.J., and Krangel, M.S.: Sequence and chromosomal location of the I-309 gene: relationship to genes encoding a family of inflammatory cytokines. $J$ Immunol 145: 2737-2744, 1990.

153. Mishkin, J.D., Taylor, B.A., and Mellman, W.J.: Glk: a locus controlling galactokinase activity in the mouse. Biochem Genet 14: 635-640, 1976.

154. Mitelman, F., Manolov, G., Manolova, Y., Billstrom, R., Heim, S., Kristoffersson, U., Mandahl, N., Ferro, M.T., and San Roman, C.: High resolution chromosome analysis of constitutional and acquired $t(15,17)$ maps $c$-erbA to subband 17q11.2. Cancer Genet Cytogenet 22: 95-98, 1986.

155. Miyatake, S., Yokota, T., Lee, F., and Arai, K.I.: Structure of the chromosomal gene for murine interleukin 3. Proc Natl Acad Sci USA 82: 316-320, 1985.

156. Moore, S.K., Appella, E., Villar, C.J., and Kozak, C.A.: Mapping of the mouse $86-\mathrm{kDa}$ heat-shock protein expressed gene (Hsp86-1) on chromosome 12 and related genes on chromosomes 3,4,9, and 11. Genomics 10: 1019-1029, 1991.

157. Morgan, W.C.: A new tail-short mutation in the mouse. $J$ Hered 4I: 208-215, 1950.

158. Munke, M., Cox, D.R., Jackson, I.J., Hogan, B.L.M., and U., F.: The murine Hox-2 cluster of homeo box containing genes maps distal on Chromosome 11 near the tail-short $(T s)$ locus. Cytogenet Cell Genet 42; 236-240, 1986.

159. Munke, M. and Francke, U.: The physical map of Mus musculus Chromosome 11 reveals evolutionary relationships with different syntenic groups of genes in Homo sapiens. J Mol Evol 25: 134-140, 1987.

160. Munke, M., Harbers, K., Jaenisch, R, and Francke, U.: Chromosomal mapping of four different integration sites of Moloney murine leukemia virus including the locus for alpha1(I) collagen in mouse. Cytogenet Cell Genet 43: 140-149, 1986.

161. Nadeau, J.: Personal communication. In Fifth International Workshop on Mouse Genome Mapping, Lunteren, The Netherlands, 1991.

162. Nadeau, J.H.: Maps of linkage and synteny homologies between mouse and man. Trends Genet 5: 82-86, 1989.

163. Nadeau, J.H., Berger, F.G., Cox, D.R., Crosby, J.L., Davisson, M.T., Ferrara, D., Fuchs, C., Hart, E., Hunihan, L.,
Lalley, P.A., Langley, S.H., Martin, G.R., Nichols, L., Phillips, S.J., Roderick, T.H., Roop, D.R., Ruddle, F.H., Skow, L.C., and Compton, J.G.: A family of type I keratin genes and the homeobox-2 gene complex are closely linked to the Rex locus on mouse Chromosome 11. Genomics 5: 454-462, 1989.

164. Nadeau, J.H., Birkenmeier, C.S., Chowdhury, K., Crosby, J.L., and Lalley, P.A.: Zinc finger protein gene complexes on mouse Chromosomes 8 and 11. Genomics 8: 469-476, 1990.

165. Nadeau, J.H., Davisson, M.T., Doolittle, D.P., Grant, P., Hillyard, A.L., Kosowsky, M., and Roderick, T.H.: Comparative map for mice and humans. Mammalian Genome I (Suppl): S461-S515, 1991.

166. Neumann, P., Hayes, L.A., and Sidman, R.L.: Linkage data: cerebellar outflow degeneration (cod). Mouse News Lett 80 : 162,1988

167. Nusse, R., Brown, A., Papkoff, J., Scambler, P., Shackleford, G., McMahon, A., Moon, R., and Varmus, H.: Establishment of Wnt- series and substitution for certain members of the Int. Cell 64: 231, 1991 .

168. Nusse, R., de Moes, J., Hilkens, J., and van Nie, R.: Localization of a gene for expression of mouse mammary tumor virus antigens in the GR/Mtv-2<-> mouse strain. $J$ Exp Med 152: 712-719, 1980.

169. Oakey, R.J., Caron, M.G., Lefkowitz, R.J., and Seldin, M.F.: Genomic organization of adrenergic and serotinin receptors in the mouse: linkage mapping of sequence related genes provides a method for examining mammalian chromosome evolution. Genomics 10: 338-344, 1991.

170. Ozcelik, T., Suedhof, T.C., and Francke, U.: Chromosomal assignments of genes for vacuolar (endomembrane) proton pump subunits VPP1/Vpp-1 (116 kDa) and VPP3/Vpp-3 (58 $\mathrm{kDa})$. Cytogenet Cell Genet, in press, 1991.

171. Pagliusi, S., Antonicek, H., Gloor, S., Frank, R., Moos, M., and Schachner, M.: Identification of a CDNA clone specific for the neural cell adhesion molecule AMOG. J Neurosci Res 22: 113-119, 1989.

172. Pajunen, L., Myllyla, R., Helaakoski, T., Pihlajaniemi, T., Tasanen, K., Hoyhtya, M., Tryggvason, K., Solomon, E., and Kivirikko, K.I.: Assignment of the gene coding for both the beta-subunit of prolyl 4-hydroxylase and the enzyme disulfide isomerase to human chromosome region $17 \mathrm{p} 11$-qter. Cytogenet Cell Genet 47: 37-41, 1988.

173. Peters, J. and Nash, H.R.: Esterases of Mus musculus: substrate and inhibition characteristics, new isozymes, and homologies with man. Biochem Genet 16: 553-569, 1978.

174. Peterson, A. and Biddle, F.: Cocked, co. Mouse News Lett 43: 19, 1970.

175. Pettenati, M.J., Le Beau, M.M., Lemons, R.S., Shima, E.A., Kawasaki, E.S., Larson, R.A., Sherr, C.J., Diaz, M.O., and Rowley, J.D.: Assignment of CSF-1 to 5q31.1 evidence for clustering of genes regulating hematopoiesis and for their involvement in the deletion of the long arm of chromosome 6 in myeloid disorders. Proc Natl Acad Sci 84: 2970-2974, 1987.

176. Ponder, B.A.J., Festing, M.F.W., and Wilkinson, M.M.: An allelic difference determines reciprocal patterns of expression of binding sites for Dolichos biflorus lectin in inbred strains of mice. J Embryol Exp Morphol 87: 229-239, 1985.

177. Popescu, N.C., King, C.R., and Kraus, M.H.: Localization of the human erbB-2 gene on normal and rearranged chromosomes 17 to bands q12-21.32. Genomics $4: 362-366,1989$.

178. Popp, R.A.: Studies on the mouse hemoglobin loci II, III, IV. J Hered 53: 73-80, 1962.

179. Popp, R.A.: Inheritance of an erythrocyte and kidney esterase in the mouse. J Hered 57: 197-201, 1966.

180. Pravtcheva, D., Rabin, M., Bartolomei, M., Corden, J., and Ruddle, F.H.: Chromosomal assignment of gene encoding the largest subunit of RNA polymerase II in the mouse. Somatic Cell Mol Genet 12: 523-528, 1986.

181. Prochazka, M., Gaskins, H.R., and Leiter, E.H.: Emv-30: a novel ecotropic MuLV present in NOD/Lt and NON/Lt strains. Mouse Genome 89: 258, 1991.

182. Rider, S.H., Gorman, P.A., Shipley, J., Roeling, H., Nusse, R., Xu, W., Sheer, D., and Solomon, E.: Localisation of the human int-4 (INT4) gene (abstract). Cytogenet Cell Genet 51 : 1066, 1989. 
183. Robert, B., Barton, P., Minty, A., Daubas, P., Weydert, A., Bonhomme, F., Catalan, J., Chazottes, D., Guenet, J.L., and Buckingham, M.: Investigation of genetic linkage between myosin and actin genes using an interspecific mouse back-cross. Nature 314: 181-183, 1985.

184. Robinson, T.J., Morris, D.J., and Ledbetter, D.H.: Chromosomal assignment and regional localization of myeloperoxidase in the mouse. Cytogenet Cell Genet 53: 83-86, 1989.

185. Roderick, T.H.: Position of jackson shaker. Mouse News Lett 47: 37, 1972 .

186. Rout, U.K. and Holmes, R.S.: Mapping of $A h d-4$ and $A$ hd -6 to Chromosome 11. Mouse News Lett 81: 54, 1988

187. Russell, E.S., Blake, S.L., and McFarland, E.C.: Characterization and strain distribution of four alleles at the hemoglobin a-chain structural locus in the mouse. Biochem Genet 7: 313$330,1972$.

188. Said, K., Jacquart, T., Montgelard, C., Sonjaya, H., Helal, A.N., and Britton-Davidian, $\mathbf{J}$.: Robertsonian house mouse populations in Tunisia: a karyological and biochemical study. Genetica 68: 151-156, 1986.

189. Sanford, J.P., Eddy, R.L., Doyle, D., and Shows, T.B.: Assignment of human asialoglycoprotein receptor gene (ASGR1) to chromosome 17p11-p13. Genomics 11: 779-781, 1991.

190. Sanford, J.P., Elliott, R.W., and Doyle, D.: Asialoglycoprotein receptor genes are linked on Chromosome 11 in the mouse. DNA 7: 721-728, 1988.

191. Santisteban, I., Povey, S., West, L.F., Parrington, J.M., and Hopkinson, D.A.: Chromosome assignment, biochemical and immunological studies on a human aldehyde dehydrogenase, ALDH3. Ann Hum Genet 49: 87-100, 1985.

192. Searle, A.G.: Tipsy, a new mutant in linkage group VII of the mouse. Genet Res 2: 122-126, 1961.

193. Searle, A.G., Beechey, C.V., Evans, E.P., and Kirk, M.: Two new X-autosome translocations in the mouse. Cytogenet Cell Genet 35: 279-292, 1983 .

194. Searle, A.G., Ford, C.E., Evans, C.V., Beechey, M.D., Burtenshaw, M.D., and Clegg, H.M.: The induction of translocations in mouse spermatozoa. I. Kinetics of dose response with acute X-irradiation. Mutat Res 22: 157-174, 1974.

195. Seharaseyon, J., Bober, E., Hsieh, C.L., Fodor, W.L., Francke, U., Arnold, H.H., and Vanin, E.F.: Human embryonic/atrial myosin alkali light chain gene: characterization, sequence and chromosomal location. Genomics 7: 289-293, 1990.

196. Seizinger, B.R.e.a.: Genetic linkage of von Recklinghausen neurofibromatosis to the nerve growth factor receptor gene. Cell 49: 589-594, 1987.

197. Showe, L.C., Ballantine, M., and Huebner, K.: Localization of the gene for the erythroid anion exchange protein, band 3 (EMPB3), to human chromosome 17. Genomics 1: 71-76, 1987.

198. Shupp Byrne, D.E. and R.L., C.: Assignment of the genes for the mouse type I procollagen to chromosome 16 using mouse fibroblast-Chinese hamster somatic cell hybrids. Somatic Cell Genet 9: 313-331, 1983.

199. Silver, J., Whitney, J.B. III, Kozak, C., Hollis, G., and Kirsch, I.: Erbb is linked to the alpha-globin locus on mouse Chromosome 11. Mol Cell Biol 5: 1784-1786, 1985.

200. Smith, A., Lalley, P.A., Killary, A.M., Ghosh-Choudhury, G., Wang, L.M., Han, E.S., Martinez, L., Naylor, S.L., and Sakaguchi, A.Y.: Sigje, a member of the small inducible gene family that includes platelet factor 4 and melanoma growth stimulatory activity, is on mouse Chromosome 11. Cytogenet Cell Genet 52: 194-196, 1989.

201. Spurr, N.K., Solomon, E., Jansson, M., Sheer, D., Goodfellow, P.N., Bodmer, W.F., and Vennstrom, B.: Chromosomal localisation of the human homologues to the oncogenes erbA and B. EMBO J 3: 159-163, 1984.

202. Stahl, J., Gearing, D.P., Willson, T.A., Brown, M.A., King, J.A., and Gough, N.M.: Structural organization of the genes for murine and human leukemia inhibitory factor. Evolutionary conservation of coding and non-coding regions. $\mathrm{J} \mathrm{Biol} \mathrm{Chem}$ 265: 8833-8841, 1990.

203. Summar, M.L., Phillips, J.A. III, Krishnamani, M.R.S., Keefer, J., Trofatter, J., Schwartz, R.C., Tsipouras, P., Willard, H., and Ullrich, A.: Protein kinase C: a new linkage marker for growth hormone and for COL1A1. Genomics 5 : 163-165, 1989.

204. Sutherland, G.R., Baker, E., Callen, D.F., Campbell, H.D., Young, Y.G., Sanderson, C.J., Garson, O.M., Lopez, A.F., and Vadas, M.A.: Interleukin-5 is at $5 \mathrm{q} 31$ and is deleted in the 5q- syndrome. Blood 71: 1150-1152, 1988.

205. Sutherland, G.R., Baker, E., Callen, D.F., Hyland, V.J., Wong, G., Clark, S., Jones, S.S., Eglinton, L.K., Shannon, M.F., Lopez, A.F., and Vadas, M.A.: Interleukin 4 is at $\mathbf{5 q} \mathbf{3} 1$ and interleukin 6 is at 7p15. Hum Genet 79: 335-337, 1988.

206. Sutherland, G.R., Baker, E., Hyland, V.J., Callen, D.F., Stahl, J., and Gough, N.M.: The gene for human leukemia inhibitory factor $(L I F)$ maps to 22q12. Leukemia 3: 9-13, 1989.

207. Swallow, D.M., Turner, V.S., and Hopkinson, D.A.: Isozymes of rodent 5 ' nucleotidase: evidence for two independent structural loci Umph-1 and Umph-2. Ann Hum Genet 47: 9-17, 1983.

208. Swaroop, A., Hogan, B.L.M., and Francke, U.: Molecular analysis of the cDNA for human SPARC/osteonectin/BM-40: sequence, expression, and localization of the gene to chromosome 5q31-q33. Genomics 2: 37-47, 1988.

209. Sweet, H.O. and Lane, P.W.: Chr 19 and Chr 11 linkages. Mouse News Lett 59: 27, 1979.

210. Takahashi, M., Yoshida, M.C., Satoh, H., Hilgers, J., Yaoita, Y., and Honjo, T.: Chromosomal mapping of the mouse IL-4 and human IL-5 genes. Genomics 4: 47-52, 1989.

211. Taylor, B.A.: RI strain distribution patterns. Mouse News Lett 77: $130,1987$.

212. Taylor, B.A. and Rowe, L.: A mouse linkage testing stock possessing multiple copies of the endogenous ecotropic murine leukemia virus genome. Genomics 5: 221-232, 1989.

213. Taylor, B.A., Rowe, L., Jenkins, N.A., and Copeland, N.G.: Chromosomal assignment of two endogenous ecotropic murine leukemia virus proviruses of the AKR/J mouse strain. $I$ Virol 56: $172-175,1985$.

214. Todd, J.A., Aitman, T.J., Cornall, R.J., Ghosh, S., Hall, J.R.S., Hearne, C.M., Knight, A.M., Love, J.M., McAleer, M.A., Prins, J.-B., Rodriguers, N., Lathrop, M., Pressey, A., DeLarato, N.H., Peterson, L.B., and Wicker, L.S.: Genetic analysis of autoimmune type 1 diabetes mellitus in mice. $\mathrm{Na}$ ture 351: 542-547, 1991.

215. Tsipouras, P., Schwartz, R.C., Phillips, J.A., III, and Willard, H.F.: A centromere-based linkage group on the long arm of human chromosome 17. Cytogenet Cell Genet 47: 109-110, 1988.

216. Tuteja, N., Danciger, M., Kilisak, I., Tuteja, R., Inana, G., Mohandas, T., Sparkes, R.S., and Farber, D.B.: Isolation and characterization of cDNA encoding the gamma-subunit of cGMP phosphodiesterase in human retina. Gene 88: 227-232, 1990.

217. Tweardy, D.J., Cannizzaro, L.A., Palumbo, A.P., Shane, S., Huebner, K., van Tuinen, P., Ledbetter, D.H., Finan, J.B., Nowell, P.C., and Rovera, G.: Molecular cloning and characterization of a cDNA for human granulocyte colonystimulating factor (G-CSF) from a glioblastoma multiform cell line and localization of the G-CSF gene to chromosome band 17q21. Oncogene Res 1:209-220, 1987.

218. Uiterdijk, H.G., Ponder, B.A.J., Festing, M.F.W., Hilgers, J., Skow, L., and Van Nie, R.: The gene controlling the binding sites of Dolichos biflorus agglutinin, D1b-1, is on Chromosome 11 of the mouse. Genet Res 47: 125-129, 1986.

219. van Tuinen, P. and Ledbetter, D.H.: Construction and utilization of a detailed somatic cell hybrid mapping panel for human chromosome 17: localization of an anonymous clone to the critical region of Miller-Dieker syndrome, deletion $17 \mathrm{p} 13$. ( $A \mathrm{~b}$ stract) Cytogenet Cell Genet 46: 708-709, 1987.

220. Watanabe, T., Masaki, S., Takahashi, N., Nishimura, M., and Kato, H.: Restriction fragment length polymorphism and chromosome mapping of a mouse homeo box gene, Hox-2.1. Biochem Genet 26: 805-813, 1988.

221. Webb, G.C., Lee, J.S., Campbell, H.D., and Young, I.G.: The genes for interleukins 3 and 5 map to the same locus on mouse Chromosome 11. Cytogenet Cell Genet 50: 107-110, 1989.

222. Weimar, W.R., lane, P.W., and Sidman, R.L.: "Vibrator" 
(vb): autosomal recessive inheritance of spongiform spinocerebellar degeneration in mice. Brain Res 251: 357-364, 1982.

223. Weydert, A., Daubas, P., Lazaridis, I., Barton, P., Garner, I., Leader, D.P., Bonhomme, F., Catalan, J., Simon, D., Guénet, J.-L., Gros, F., and Buckingham, M.E.: Genes for skeletal muscle myosin heavy chains are clustered and are not located on the same mouse chromosome as a cardiac myosin heavy chain gene. Proc Natl Acad Sci USA 82: 7183-7187, 1985.

224. Whitney, J.B. III and Russell, E.S.: Linkage of genes for adult alpha-globin and embryonic alpha-like globin chains. Proc Natl Acad Sci USA 77: 1087-1090, 1980.

225. Wilson, D.E., Woodard, D., Sandler, A., Erickson, J., and Gurney, A.: Provisional assignment of the gene for uridine monophosphatase-2 (Umph-2) to mouse Chromosome 11. Biochem Genet 25: 1-6, 1987.

226. Wilson, S.D., Billings, P.R., D'Eustachio, P., Fournier, R.E.K., Geissler, E., Lalley, P.A., Burd, P.R., Housman, D.E., Taylor, B.A., and Dorf, M.E.: Clustering of cytokine genes on mouse Chromosome 11. J Exp Med 171: 1301-1314, 1990.

227. Winking, H. and Dulic, B.A.G., A.: Mouse News Lett 60: 55, 1979.
228. Winking, H., Noack, G., Gropp, A., and Capanna, E.: Mouse News Lett 60: 55, 1979.

229. Xu, W., Gorman, P.A., Rider, S.H., Hedge, P.J., Moore, G., Prichard, C., Sheer, D., and Solomon, E.: Construction of a genetic map of human chromosome 17 by use of chromosomemediated gene transfer. Proc Natl Acad Sci 85: 8563-8567, 1988.

230. Yang-Feng, T.L., Xue, F., Zhong, W., Cotecchia, S., Frielle, T., Caron, M.G., Lefkowitz, R.J., and Francke, U.: Chromosomal organization of adrenergic receptor genes. Proc Natl Acad Sci USA 87: 1516-1520, 1990.

231. Zabel, B.U., Fournier, R.E., Lalley, P.A., Naylor, S.L., and Sakaguchi, A.Y.: Cellular homologs of the avian erythroblastosis virus erb-A and erb-B genes are syntenic in mouse but asyntenic in man. Proc Natl Acad Sci USA 81: 4874-4878, 1984.

232. Zakut-Houri, R., Oren, M., Bienz, B., Lavie, V., Hazum, S., and Givol, D.: A single gene and a pseudogene for the cellular tumor antigen p53. Nature 306: 594-597, 1983.

233. Zech, L., Evans, E.P., Ford, C.E., and Gropp, A.: Banding patterns in the mitotic chromosomes of tobacco mouse. Exp Cell Res 70: 263-268, 1972. 